\title{
A Solid-State Luminescent Cd(II) Supramolecular Coordination Framework Based on Mixed Luminophores as a Sensor for Discriminatively Selective Detection of Amine Vapors
}

Sujitra Tunsrichon, ${ }^{a}$ Chattarika Sukpattanacharoen ${ }^{b}$ Daniel Escudero, ${ }^{c}$ Nawee Kungwan ${ }^{b, d}$ Sujittra Youngme, ${ }^{a}$ and Jaursup Boonmak ${ }^{a} *$

${ }^{a}$ Materials Chemistry Research Center, Department of Chemistry and Center of Excellence for Innovation in Chemistry, Faculty of Science, Khon Kaen University, Khon Kaen, 40002, Thailand.

${ }^{b}$ Department of Chemistry, Faculty of Science and Graduate School, Chiang Mai University, Chiang Mai, 50200, Thailand

${ }^{c}$ Department of Chemistry, KU Leuven, Celestijnenlaan 200F, B-3001 Leuven, Belgium

${ }^{d}$ Center of Excellence in Material Science and Technology, Chiang Mai University, Chiang Mai, 50200, Thailand

KEYWORDS. Supramolecular coordination framework; Luminescent sensor; Amine vapors; Cd(II); 4-aminosalicylate 
ABSTRACT. A novel Cd(II) supramolecular coordination framework containing mixed functionalized luminophore ligands, namely $\left[\mathrm{Cd}(\mathrm{AS})_{2}(\mathrm{phen})_{2}\right] \mathrm{EtOH}$ or $\mathbf{1}$ (AS = 4aminosalicylate, phen =1,10-phenanthroline, EtOH = ethanol), was successfully synthesized as a solid-state luminescent sensor for detection of amine vapors. The single-crystal X-ray diffraction analysis revealed that 1 possesses a 3D supramolecular framework enclosing ethanol molecule in the lattice. The supramolecular structure is well stabilized by various noncovalent intermolecular interactions through functional groups of ligands. Compound 1 shows an intense yellow solid-state emission and displays a reversibly discriminative luminescent response to $\mathrm{NH}_{3}$ and ethylenediamine (EDA) vapors through very large blueshifted luminescent spectra with distinguishable emission colors under UV light. This work reports the first time for selective luminescent sensing of $\mathrm{NH}_{3}$ and EDA vapors with considerably different emission color change. A sensing mechanism has been confirmed by DFT and TD-DFT calculations that agrees well with the experimental results. Also, 1 exhibits a good recyclability over 5 cycles for sensing of $\mathrm{NH}_{3}$ and EDA vapors. 


\section{INTRODUCTION}

Among volatile organic compounds (VOCs), amines are one of the most dangerous small molecules that have been extensively used as chemical raw materials in the industries of pharmaceutics, herbicides and fertilizers. ${ }^{1}$ The colorless amine molecules that leak out from the industries can easily vaporize at room temperature. Beside environmental contamination, amines are carcinogenic and very harmful to human exposure through breathing or skin contact. $^{2-3}$ Therefore, the selective detection of the organic amine vapor in the environment is definitely required. Even though several analytical methods have been applied for sensing of hazardous amine vapors, ${ }^{4-5}$ luminescence-based detection methods have attracted more attention because of their simple signal transduction, rapid response and highly selectivity and sensitivity. ${ }^{6}$ The luminescent sensors commonly shows a "turn-off" or "turn-on" mechanism upon amine detection. These signal outputs are rarely specific and more difficult to detect. ${ }^{7-8}$ A much more attractive mechanism is the shift of luminescent wavelength upon interaction with the analytes, leading to a visibly change of the emission color. Luminescent sensors undergoing an emission color change upon amine detection have rarely been reported. ${ }^{9-10}$ Owing to the same chemical and physical characteristics of the amines, the development of selective sensors is not straightforward. ${ }^{11-12}$ Consequently, the construction of highly selective luminescent sensor for amine vapors becomes a challenging topic.

Supramolecular coordination frameworks are coordination compounds containing intermolecular noncovalent interactions such as hydrogen-bonding, $\pi-\pi$, and $\mathrm{C}-\mathrm{H}-\pi$ interactions, which act as directional interactions to construct the final supramolecular framework. ${ }^{13-14}$ The assembly of luminescent supramolecular network is typically based on the coordination of luminophore ligands together with $\mathrm{d}^{10}$ metal centers. ${ }^{15}$ Importantly, the luminophore ligands must contain the functional groups facilitating several intermolecular interactions that can directly drive the organization and rearrangement of luminophores in the framework. ${ }^{16}$ The reordering of intermolecular interactions in the flexible supramolecular structure triggered by analytes can eventually lead to a change of the luminescent color. In recent years, the luminescent sensors in liquid phase have been mainly used to detect amines. ${ }^{17-}$ 19 The solid-state luminescent supramolecular coordination frameworks for amine detection are rare. ${ }^{8,20-26}$ Notably, for real-time detection, the luminescent probe in a solid phase is more practical use than a liquid phase. ${ }^{27}$

Herein, we reported a novel luminescent supramolecular coordination framework, $\left[\mathrm{Cd}(\mathrm{AS})_{2}(\text { phen })_{2}\right] \mathrm{EtOH}$ or 1 by introducing 4-aminosalicylate (AS) and 1,10-phenanthroline (phen) as luminophores ligands. Apart from the luminophoric property of ligands, both ligands 
contain various functional groups that can facilitate a stable 3D supramolecular network via various noncovalent interactions. The resulting solid-state $\mathbf{1}$ demonstrated a visible yellow luminescence. Compound 1 exhibits a highly selective detection of $\mathrm{NH}_{3}$ and EDA vapors with distinguishable emission colors. The sensing mechanism has been established by a combined experimental and theoretical approach. Remarkably, the luminescent response of 1 shows a reversible process.

\section{EXPERIMENTAL SECTION}

Materials and physical methods. All chemicals were commercially purchased and used in all experiments as received without further purification. The powder X-ray diffraction (PXRD) patterns were taken on a PANalytical EMPYREAN X-ray diffractometer in the $2 \theta$ range 5-50 using $\mathrm{Cu} \mathrm{K \alpha}(\lambda=1.5406 \AA)$ as a source and a recording speed of $0.5 \mathrm{~s} / \mathrm{step}$. A standard Pike ATR cell on a Bruker Tensor 27 FT-IR spectrophotometer was performed to record the ATRFT-IR spectra (ATR is attenuated total reflectance) in the range 4000-600 $\mathrm{cm}^{-1}$. Elemental analyses $(\mathrm{CHN})$ were measured on a PerkinElmer PE 2400CHNS apparatus. The thermograms were collected via thermogravimetric analysis (TGA) measurements using TG-DTA 2010S MAC thermal analyzer at $30-800{ }^{\circ} \mathrm{C}$ under a nitrogen atmosphere with a heating rate of $10{ }^{\circ} \mathrm{C}$ $\min ^{-1}$. The solid-state UV-Vis absorption spectra were obtained in the range of 200-800 nm using a PerkinElmer Lambda2S spectrophotometer. A Shimadzu RF-6000 Spectro fluorophotometer equipment with a continuous Xe lamp at room temperature was used to collect the solid-state luminescent spectra.

Synthesis of $\left[\mathbf{C d}(\mathbf{A S})_{2}(\text { phen })_{2}\right]$ EtOH (1). The ethanolic solution (2 $\left.\mathrm{mL}\right)$ of 1,10 phenanthroline monohydrate (phen) $(0.1 \mathrm{mmol}, 19.8 \mathrm{mg})$ was carefully layered over the mixed aqueous solution $(4 \mathrm{~mL})$ containing sodium dihydrate 4-aminosalicylate or NaAS (0.2 mmol, $35 \mathrm{mg})$ and $\mathrm{Cd}\left(\mathrm{NO}_{3}\right)_{2} \cdot 4 \mathrm{H}_{2} \mathrm{O}(0.1 \mathrm{mmol}, 30.84 \mathrm{mg})$ in $15 \mathrm{~mL}$ of glass vial. The vial was capped and allowed to stand undisturbed at room temperature. After 4 days, the yellow block-shaped crystals of 1 were completely formed with a yield of 28\% (11.60 mg) based on phen ligand. Anal. Calcd for $\mathrm{CdC}_{40} \mathrm{H}_{34} \mathrm{~N}_{6} \mathrm{O}_{7}$ : C, 57.89; H, 3.74; N, 10.39\%. Found: C, 58.10; H, 3.58; N, 10.44\%. ATR-FT-IR ( $\left.\mathrm{cm}^{-1}\right): 3455(\mathrm{br}), 3347(\mathrm{br}), 3233(\mathrm{br}), 1632(\mathrm{~m}), 1570(\mathrm{~s}), 1380(\mathrm{~s})$, 1192(w), 837(s), 727(s).

$\mathrm{X}$-ray data collection and structural refinement details. A data collection for $\mathbf{1}$ was carried out on a Bruker D8 Quest PHOTON100 CMOS detector equipped with a graphite monochromated Mo K $\alpha$ radiation. The crystallographic data of 1 was collected by the APEX2 
program. ${ }^{28}$ The raw data frame integration was carried out by the SAINT program ${ }^{29}$, with the intensities collected for Lorentz and polarization effects. An empirical absorption correction was then applied using the SADABS program. ${ }^{30}$ The direct methods were performed for solving the structure solution using the SHELXTL crystallographic software. ${ }^{31}$ Subsequently, the refinement method of a full-matrix least-squares on $F^{2}$ was used to refine the structure. All non-hydrogen atoms were refined with anisotropic thermal parameters. All $\mathrm{H}$ atoms were put in geometrically calculated positions and refined isotropically. A summary of the crystallographic data and refinement, the selected bond distances and angles, and intermolecular hydrogen bonds for $\mathbf{1}$ are presented in Table 1 and S1-S3.

Solid-state luminescent sensing experiment. All solid-state luminescent sensing experiments were examined at room temperature. The diagram of vapor-sensing experiment was illustrated in Scheme S1. Firstly, each amine vapor was prepared by evaporation of $3 \mathrm{ml}$ of the commercial amine solution in sealed small glass vial of $15 \mathrm{ml}$. The detail of concentration of amine solutions was presented in Table S4. The ground sample of $\mathbf{1}$ (6 mg) was added into the small glass tube $(1 \mathrm{~mL})$. It was then exposed to the amine vapor in the sealed vial. The solid-state luminescent spectrum of the samples was recorded upon excitation at $368 \mathrm{~nm}$.

Computational details. All calculations for $\left[\mathrm{Cd}(\mathrm{AS})_{2}(\text { phen })_{2}\right] \mathrm{EtOH} \quad(\mathbf{1})$, $\left[\mathrm{Cd}(\mathrm{AS})_{2}(\text { phen })_{2}\right] \mathrm{EtOH}\left(\mathrm{NH}_{3}\right)\left(\mathrm{H}_{2} \mathrm{O}\right)\left(\mathbf{1} @ \mathrm{NH}_{3}\right)$, and $\left[\mathrm{Cd}(\mathrm{AS})_{2}(\text { phen })_{2}\right] \mathrm{EtOH}(\mathrm{EDA})_{2}(\mathbf{1} @ \mathrm{EDA})$ are based on density functional theory (DFT) and time-dependent DFT (TD-DFT). The geometries optimizations of $1,1 @ E D A$, and $1 @ \mathrm{NH}_{3}$ in the ground state $\left(\mathrm{S}_{0}\right)$ and excited state $\left(\mathrm{S}_{1}\right)$ were carried out with DFT and TD-DFT, respectively; using the Becke's three-parameter hybrid exchange functional combined with the Lee-Yang-Parr correlation functional $(\mathrm{B} 3 \mathrm{LYP}),{ }^{32-34}$ in combination with the $6-31 \mathrm{G}(\mathrm{d})$ atomic basis set for all non-metal atoms. Relativistic effects were included for the mental $\mathrm{Cd}$ atoms by using ecp-mweb-28 pseudopotential. ${ }^{35}$ All optimized structures were confirmed to be local minima by normal mode analysis. The UV-Vis absorption spectra were simulated through the calculation of the first 40 singlet-to-singlet TD-B3LYP vertical transitions at the $\mathrm{S}_{0}$ geometries. The absorption, emission spectra, and the orbital contributions were generated with GaussSum package. ${ }^{36}$ All calculations were performed using Gaussian 16 program package. ${ }^{37}$ 
Table 1. Crystallographic data of 1.

\begin{tabular}{|c|c|}
\hline & 1 \\
\hline Formula & $\mathrm{CdC}_{40} \mathrm{H}_{34} \mathrm{~N}_{6} \mathrm{O}_{7}$ \\
\hline Molecular weight & 823.14 \\
\hline $\mathrm{T}(\mathrm{K})$ & 298(2) \\
\hline Crystal system & monoclinic \\
\hline Space group & $\mathrm{P} 2_{1} / \mathrm{n}$ \\
\hline $\mathrm{a}(\AA)$ & $13.6303(7)$ \\
\hline $\mathrm{b}(\AA)$ & $16.7314(8)$ \\
\hline c $(\AA)$ & $15.8873(6)$ \\
\hline$\alpha\left({ }^{\circ}\right)$ & 90 \\
\hline$\beta\left(^{\circ}\right)$ & $103.919(1)$ \\
\hline$\gamma\left({ }^{\circ}\right)$ & 90 \\
\hline $\mathrm{V}\left(\AA^{3}\right)$ & $3516.8(3)$ \\
\hline $\mathrm{Z}$ & 4 \\
\hline$\rho_{\text {cald }}\left(\mathrm{g} \mathrm{cm}^{-3}\right)$ & 1.555 \\
\hline$\mu(\operatorname{Mo~K} \alpha)\left(\mathrm{mm}^{-1}\right)$ & 0.683 \\
\hline Data collected & 74492 \\
\hline Unique data $\left(\mathrm{R}_{\text {int }}\right)$ & $6428(0.1065)$ \\
\hline $\mathrm{R}_{1}{ }^{\mathrm{a}} / \mathrm{wR}_{2}{ }^{\mathrm{b}}[\mathrm{I}>2(\mathrm{I} \sigma)]$ & $0.0348 / 0.0707$ \\
\hline $\mathrm{R}_{1}{ }^{\mathrm{a}} / \mathrm{wR}_{2}{ }^{\mathrm{b}}[$ all data $]$ & $0.0564 / 0.0780$ \\
\hline GOF & 1.049 \\
\hline Maximum/minimum electron density $\left(\mathrm{e} \AA^{-3}\right.$ ) & $0.60 /-0.29$ \\
\hline
\end{tabular}

\section{RESULTS AND DISCUSSION}

Crystal structure of $\left[\mathrm{Cd}(\mathrm{AS})_{2}(\text { phen })_{2}\right]$ EtOH (1). Single-crystal structure determination reveals that 1 crystallizes in a monoclinic with $\mathrm{P} 2{ }_{1} / \mathrm{n}$ space group. The asymmetric unit of $\mathbf{1}$ contains one $\mathrm{Cd}(\mathrm{II})$ ion, two AS and two phen ligands, and one EtOH molecule. As shown in Figure 1a, the heptacoordinated $\mathrm{Cd}(\mathrm{II})$ center is completed by three carboxylate $\mathrm{O}$ atoms from two deprotonated AS ligands and four pyridyl $\mathrm{N}$ atoms from two different chelated phen with the average $\mathrm{Cd}-\mathrm{N}$ distances of 2.383(2)- 2.488(2) $\AA$, constructing a capped trigonal prismatic $\mathrm{CdO}_{3} \mathrm{~N}_{4}$ geometry of a discrete $\mathrm{Cd}(\mathrm{II})$ monomeric complex. Two coordinated AS ligands exhibit the different coordination modes through carboxylate groups including chelation bridging mode with bond distances of $\mathrm{Cd} 1-\mathrm{O} 1=2.583(2) \AA$ and $\mathrm{Cd} 1-\mathrm{O} 2=2.397(2) \AA$, and monodentate fashion with $\mathrm{Cd} 1-\mathrm{O} 5$ distance of 2.242(2) Å. Moreover, the uncoordinated hydroxyl and amino groups of AS can provide the remarkable feature of supramolecular assembly via the noncovalent intermolecular interactions among the monomeric units. As depicted in Figure 1b, each 1D supramolecular chain along the $b$ axis is generated via $\pi \cdots \pi$ interactions between the centroids of AS and central phenyl rings of phen with face-to-face distance of 3.660(2) $\AA$ and the $\mathrm{Cd} \cdots \mathrm{Cd}$ distance of 9.655(2) $\AA$. Each individual 1D chain is 
further packed into another via weak hydrogen bonds between the adjacent AS in which $\mathrm{N}$ atoms from amino groups serve as a hydrogen donor and $\mathrm{O}$ atoms from hydroxyl groups serve as an $\mathrm{H}$-acceptor $(\mathrm{N} 2-\mathrm{H} 2 \mathrm{~A} \cdots \mathrm{O} 3)$ with $\mathrm{D} \cdots \mathrm{A}$ distance value of 3.041(3) $\AA$ to form 2D layers in $b c$ plane (Figure 2a). Interestingly, the hydrogen bond of $\mathrm{N} 1-\mathrm{H} 1 \mathrm{~B} \cdots \mathrm{O} 8$ between lattice $\mathrm{EtOH}$ molecules and amino groups of AS ligand are observed. Such the weak noncovalent bonds assist the complex causing a more stable $2 \mathrm{D}$ sheet of $\mathbf{1}$ (Figure $2 \mathrm{a}$ and $\mathrm{S} 1$ ). The detailed of hydrogen bonds in $\mathbf{1}$ are presented in Table S3. Finally, these 2D layers are stacked via strong interlayer $\mathrm{C}-\mathrm{H} \cdots \pi$ interactions among the centroid and hydrogen atom of the adjacent phen units with $\mathrm{C} 36-\mathrm{H} 36 \cdots \mathrm{Cg}$ distance of $2.618 \AA$ A. Additionally, the $\mathrm{N} 1-\mathrm{H} 1 \mathrm{~A} \cdots \mathrm{O} 4$ hydrogen bond between the amino group and the uncoordinated carboxylate oxygen atom of AS further stabilizes the 3D supramolecular framework of 1 (Figure 2b and S2).

Characterizations. ATR-FT-IR spectrum of 1 reveals the characteristic peaks of the functional groups of ligands (Figure S3). The vibrational modes of $v_{\mathrm{as}}\left(\mathrm{COO}^{-}\right)$and $v_{\mathrm{s}}\left(\mathrm{COO}^{-}\right)$ from AS ligand occur at 1570 and $1380 \mathrm{~cm}^{-1}$, respectively. The vibrational peaks of AS ligand were further observed in the range of 3200-3500 and $1192 \mathrm{~cm}^{-1}$ which are consistent with the overlapped peaks of $v\left(\mathrm{NH}_{2}\right)$ and $v(\mathrm{OH})$, and $v(\mathrm{C}-\mathrm{O})$, respectively, while the characteristic peaks of phen ligand including $v(\mathrm{C}=\mathrm{N})$ and $v\left(\right.$ ring) occurred at 1644,846 and $732 \mathrm{~cm}^{-1}$, respectively. Compared with the free NaAS and phen, a shift of the spectra in the region of $v\left(\mathrm{COO}^{-}\right), v(\mathrm{C}=\mathrm{N})$ and $v($ ring $)$ to lower energy is attributed to the coordination of AS and phen to the metal center. The appearance of $v(\mathrm{C}-\mathrm{O})$ at $1192 \mathrm{~cm}^{-1}$ and $\delta(\mathrm{OH})$ at $1380 \mathrm{~cm}^{-1}$ for 1 in a higher energy region comparing with free ligands is due to the lattice EtOH molecule in $\mathbf{1}$.

Thermal gravimetric analysis of $\mathbf{1}$ was carried out in the range of $30-800{ }^{\circ} \mathrm{C}$ under nitrogen gas (Figure S4). The thermal stability of 1 is up to $160{ }^{\circ} \mathrm{C}$. Then, two coordinated AS ligands and one lattice EtOH molecule were decomposed in the region of $160-347^{\circ} \mathrm{C}$ showing weight loss of $42.53 \%$ (Calc. $42.55 \%$ ), after that the framework was continuously collapsed. Powder X-ray diffraction (PXRD) of $\mathbf{1}$ demonstrates that the as-synthesized PXRD pattern matches well with the simulated pattern from single-crystal structure data, confirming the crystalline phase purity of 1 (Figure S12). 


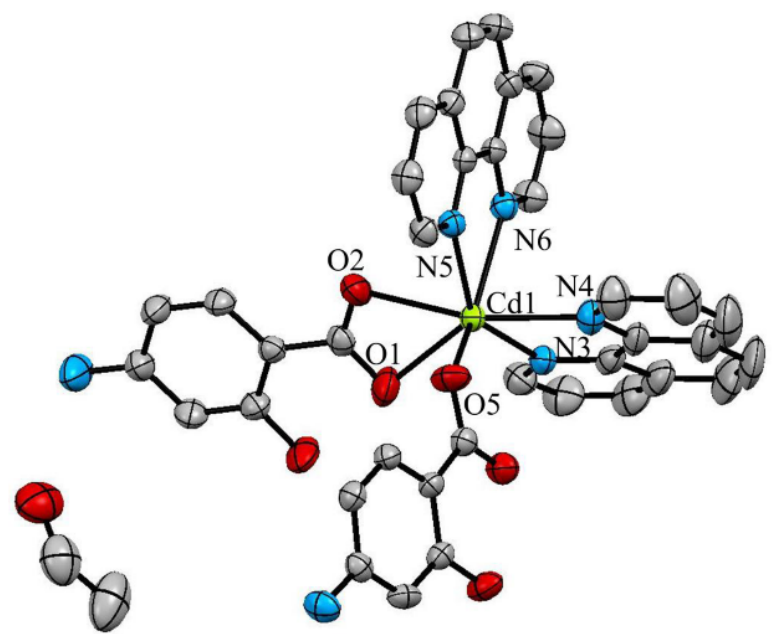

(a)

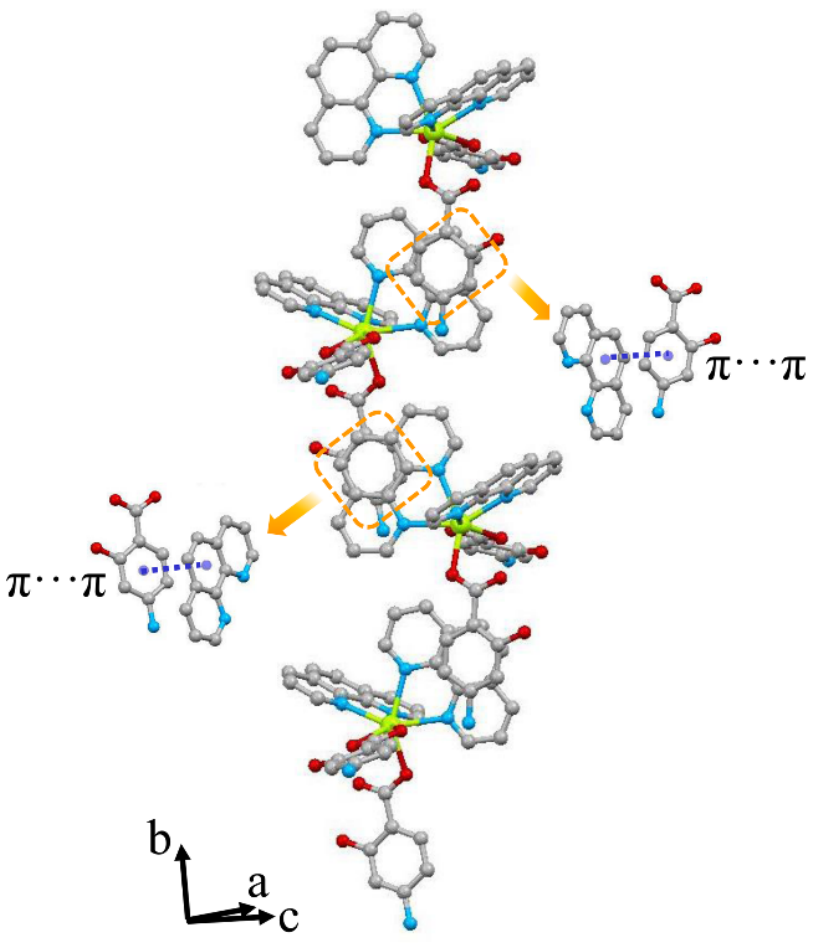

(b)

Figure 1. (a) Crystal structure of 1 showing a 50\% probability level of ellipsoids. All hydrogen atoms are omitted for clarity. (b) The 1D supramolecular chain of $\mathbf{1}$ formed via $\pi \cdots \pi$ interactions (dashed lines). 


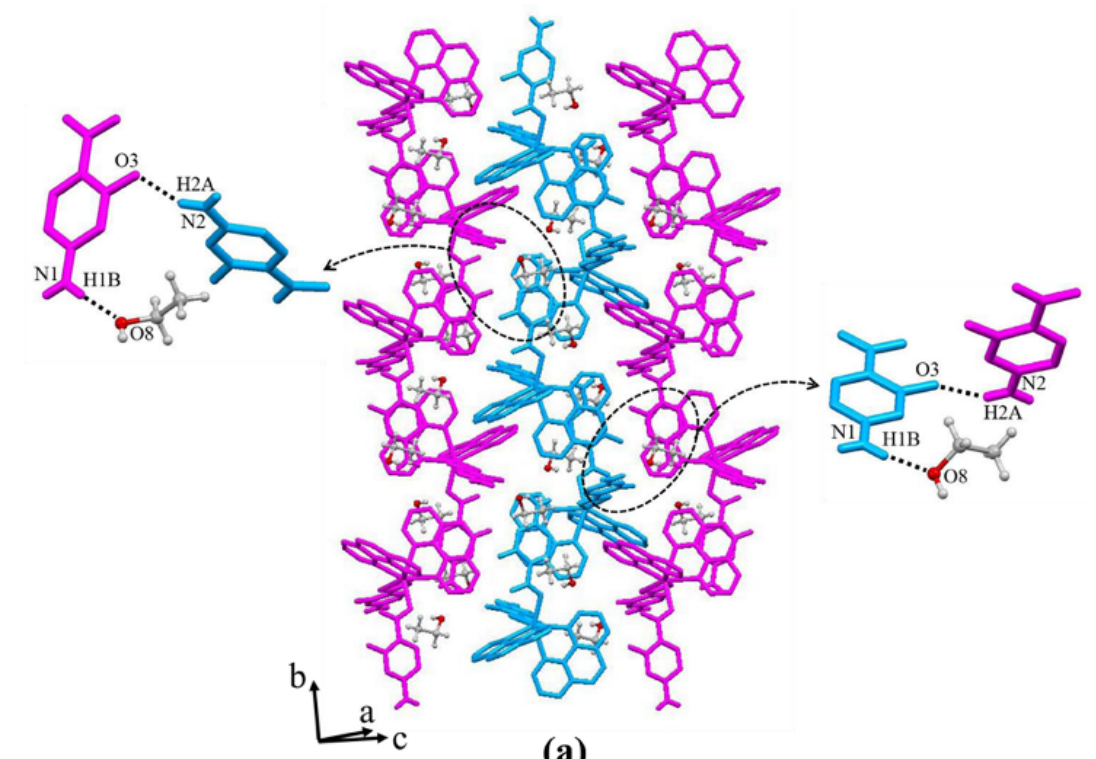

(a)

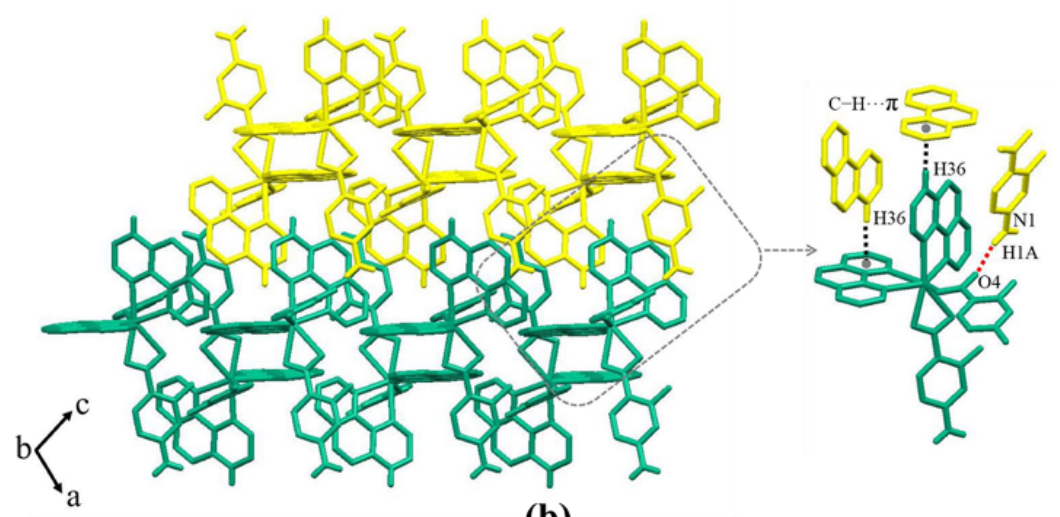

(b)

Figure 2. (a) The assembly of $2 \mathrm{D}$ supramolecular layers of 1 through hydrogen bonds. (b) 3D supramolecular framework of 1 with hydrogen bonding (red dashed line) and $\mathrm{C}-\mathrm{H} \cdots \pi$ interactions (black dashed line).

Photoluminescence property of 1 . Since the self-assembly of mix luminophores and $\mathrm{d}^{10}$ metal centers can significantly construct the luminescent coordination compounds, thus solidstate photoluminescence properties (PL) of 1 were investigated at room temperature. As illustrated in Figure 3a, compound 1 exhibits an emission band at $534 \mathrm{~nm}$ upon excitation at $368 \mathrm{~nm}$, showing intense yellow luminescence for naked eyes. The observed photoluminescence is caused by the luminophores-centered electronic transition (see the computational studies). Conversely, the luminescence spectra of free phen $\left(\lambda_{\mathrm{em}}=416 \mathrm{~nm}\right)$ and free AS ligands $\left(\lambda_{\mathrm{em}}=408 \mathrm{~nm}\right)$ were observed in the blue region that originate from $\mathrm{n} \pi *$ and/or $\pi \pi^{*}$ electronic transitions. ${ }^{38}$ Overall, the large bathochromic shift in the emission spectrum of 1 (Figure 3b) originates from a ligand-to-ligand charge (LLCT) transition, as highlighted from our computational studies (see below). ${ }^{38-40}$ 
(a)

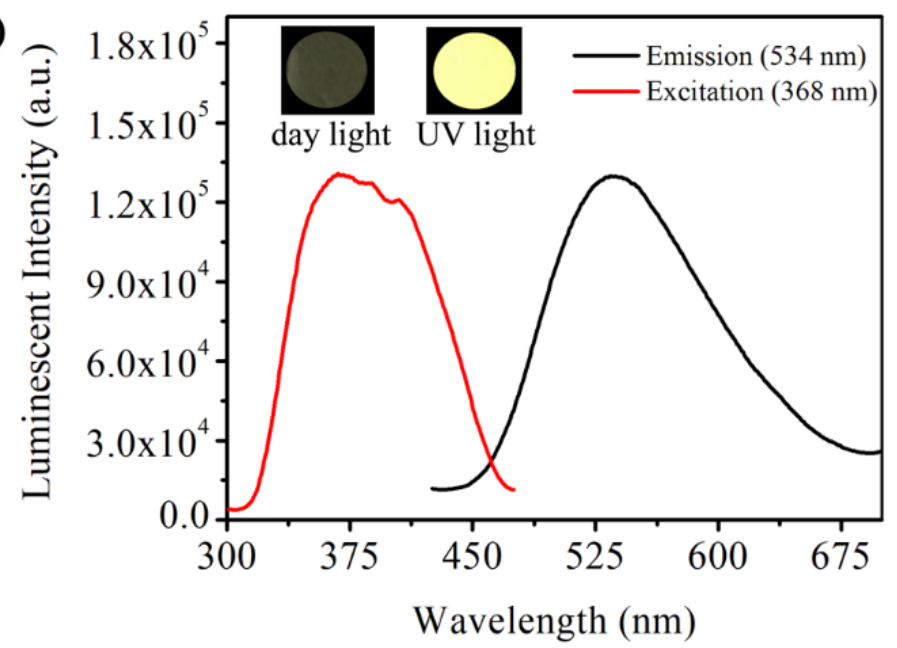

(b)

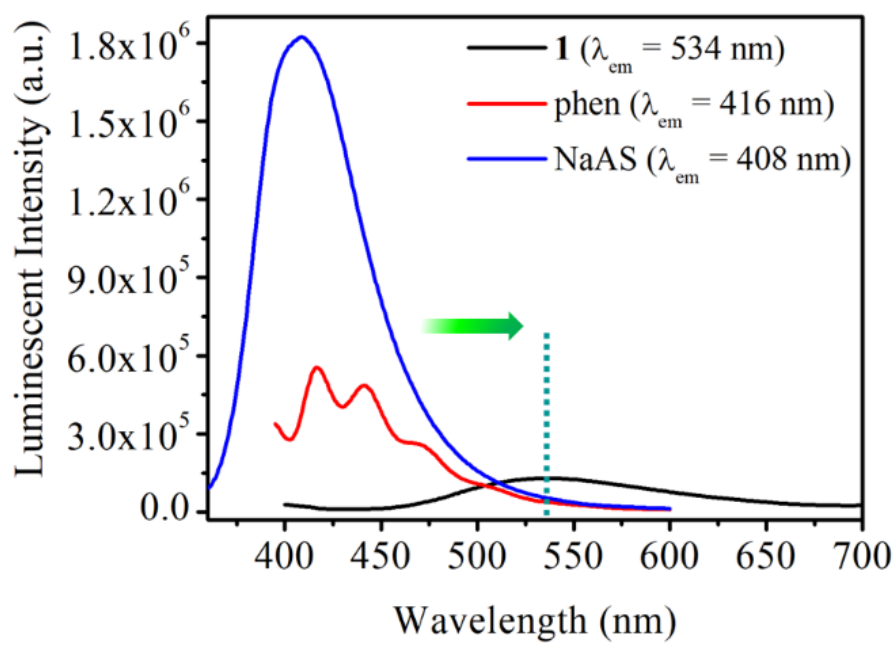

Figure 3. (a) Solid-state emission and excitation bands of 1 and the images of emission color of 1 under day light and UV light (inset). (b) Solid-state PL spectra of 1 ( $\lambda_{\text {ex }} 368 \mathrm{~nm}$ ), phen $\left(\lambda_{\text {ex }} 375 \mathrm{~nm}\right)$, and NaAS $\left(\lambda_{\text {ex }} 344 \mathrm{~nm}\right)$.

Luminescent sensing of amine vapors. Based on the above prominent solid-state luminescence property in the visible region as well as the unprecedented supramolecular framework of $\mathbf{1}$, thus, its solid-state luminescent sensing ability for amine vapors was explored. Remarkably, when ground powder of $\mathbf{1}$ was treated with the vapors of ammonia $\left(\mathrm{NH}_{3}\right)$, ethylenediamine (EDA), methylamine (MA), ethylamine (EA), diethylamine (DEA), triethylamine (TEA), diethylenetriamine (DETA), benzylamine (BYA), aniline (AN), and pyridine (Py), in the closed vials for $2 \mathrm{~h}$ at room temperature, complex $\mathbf{1}$ exhibited selective luminescent detection of $\mathrm{NH}_{3}$ and EDA without the interferences from other amines. Notably, only the emission band of the $\mathrm{NH}_{3}$-exposed sample $\left(1 @ \mathrm{NH}_{3}\right)$ and the EDA-exposed sample (1@EDA) display a large blue shift by $\sim 85 \mathrm{~nm}\left(\lambda_{\mathrm{em}}=449 \mathrm{~nm}\right)$ and $\sim 54 \mathrm{~nm}\left(\lambda_{\mathrm{em}}=480 \mathrm{~nm}\right)$, respectively, compared to that of the original $1\left(\lambda_{\mathrm{em}}=534 \mathrm{~nm}\right)$ (Figure $\left.4 \mathrm{a}\right)$. The large blue-shift in emission spectra results in a color change from yellow to dark blue for $\mathbf{1} @ \mathrm{NH}_{3}$ and cyan for 
1@EDA, which can be visibly noticeable with the naked eye under UV light, corresponding well with the CIE chromaticity diagram (Table S5 and Figure 4b). Because the selectivity is one of the key parameters to attain high-performance luminescent sensors, the sensing selectivity of $\mathbf{1}$ toward other common volatile organic compounds (VOCs) was also investigated via exposure to thirteen gases in the same experimental condition. Compound $\mathbf{1}$ is not sensitive to the common VOCs and the emission bands of the samples did not undergo any changes (Figure S5). Thus, 1 can be only considered as an efficient chemical sensor for $\mathrm{NH}_{3}$ and EDA detection. To the best of our knowledge, the shift of emission bands in this work is the largest spectral change for $\mathrm{NH}_{3}$ and EDA detections. ${ }^{9-12,17,41-49}$ Also, this work reports the first time for selective luminescent sensing of $\mathrm{NH}_{3}$ and EDA vapors with considerably different emission color change (Table 2).

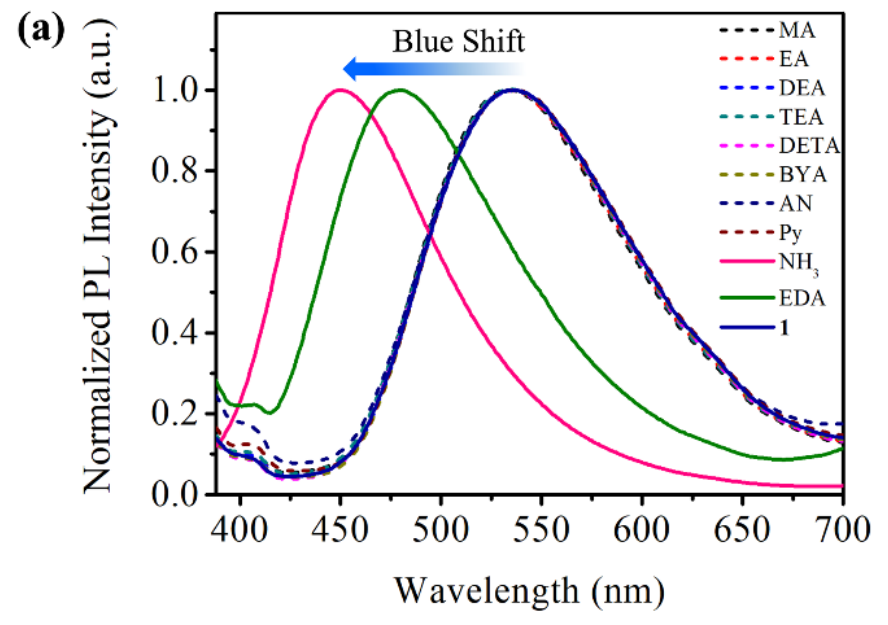

(b)

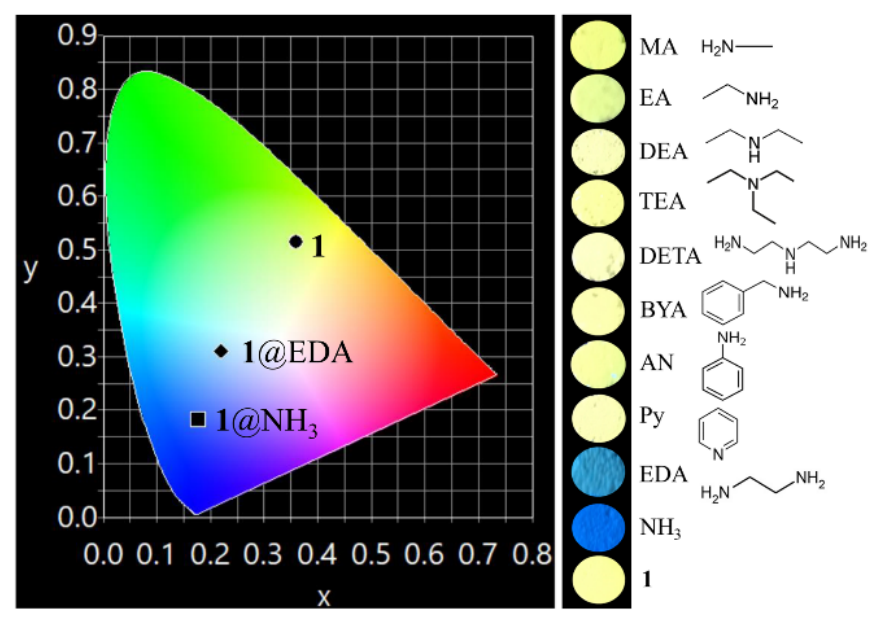

Figure 4. (a) Solid-state PL spectra $\left(\lambda_{\text {ex }} 368 \mathrm{~nm}\right.$ ), and (b) CIE chromaticity coordinates, and the images of emission color of $\mathbf{1}$ under UV light after exposure to different amine vapors at room temperature. 
Table 2. Comparison of the shifted luminescent bands of the solid-state coordination based luminescent sensors for amine detection.

\begin{tabular}{|c|c|c|c|c|c|}
\hline Compounds & Media & $\begin{array}{c}\text { Selective } \\
\text { amine } \\
\text { analytes }\end{array}$ & $\begin{array}{c}\text { The shift of } \\
\text { emission } \\
\text { wavelength }(\mathrm{nm})\end{array}$ & $\begin{array}{c}\text { The shift of } \\
\text { emission color } \\
\text { (CIE- } \Delta \mathbf{X}, \Delta \mathbf{Y})\end{array}$ & References \\
\hline \multirow{2}{*}{$\begin{array}{l}\left\{\left[\left(\mathrm{CH}_{3}\right)_{2} \mathrm{NH}_{2}\right]\left[\mathrm{Mg}_{3}(\mathrm{OH})\right.\right. \\
\left.\left.(\mathrm{DHBDC})_{3}(\mathrm{TPP})\right]\right\}_{\mathrm{n}}\end{array}$} & DMA & $\mathrm{NH}_{3}$ & Red shift $\sim 35$ & b & \multirow{2}{*}{17} \\
\hline & vapor & $\mathrm{NH}_{3}$ & Red shift $\sim 35$ & $b$ & \\
\hline \multirow{2}{*}[(\mathrm{CH}_{3})_{2}\mathrm{NH}_{2}]{$_{4}\left[\mathrm{Cd}_{2}(\mathrm{~L})\right] \cdot 4 \mathrm{H}_{2} \mathrm{O}$} & \multirow{2}{*}{ vapor } & $\mathrm{NH}_{3}$ & Blue shift $\sim 23$ & $b^{b}$ & \multirow{4}{*}{12} \\
\hline & & EA & Red shift $\sim 41$ & $b$ & \\
\hline \multirow{2}{*}[(\mathrm{CH}_{3})_{2}\mathrm{NH}_{2}]{$_{4}\left[\mathrm{Zn}_{2}(\mathrm{~L})\right] \cdot 2 \mathrm{DMF} \cdot 6 \mathrm{H}_{2} \mathrm{O}$} & \multirow{2}{*}{ vapor } & $\mathrm{NH}_{3}$ & Blue shift $\sim 24$ & $b$ & \\
\hline & & EA & Red shift $\sim 20$ & $b^{b}$ & \\
\hline$\left[\mathrm{Zn}(\mathrm{tp})(\mathrm{RdmB})\left(\mathrm{H}_{2} \mathrm{O}\right)\right]$ & \multirow{2}{*}{$\mathrm{Py}^{b}$} & Py & Blue shift $\sim 65$ & $b$ & \multirow{2}{*}{50} \\
\hline$[\mathrm{Cd}(\mathrm{tp})(\mathrm{RdmB})]$ & & Py & Blue shift $\sim 96$ & $b$ & \\
\hline \multirow{7}{*}{$\mathrm{Eu}_{4} \mathrm{~Tb}_{6}(\mathrm{acac})_{\mathrm{n}} @ \mathrm{NZL}$} & \multirow{7}{*}{ vapor } & TEA & \multirow{7}{*}{ Red shift ${ }^{c}$} & \multirow{7}{*}{ b } & \multirow{7}{*}{11} \\
\hline & & BYA & & & \\
\hline & & $\mathrm{n}-\mathrm{BuNH}_{2}$ & & & \\
\hline & & $\mathrm{t}-\mathrm{BuNH}_{2}$ & & & \\
\hline & & EDA & & & \\
\hline & & AN & & & \\
\hline & & MAN & & & \\
\hline$\left[\mathrm{Cu}_{6}\left(\mu_{3}-\mathrm{I}\right)_{6}\left(\mu_{3-} \mathrm{PTAQO}\right)_{2}\right]_{\mathrm{n}}$ & vapor & AN & Red shift $^{c}$ & b & 10 \\
\hline \multirow{10}{*}{$\begin{array}{l}\mathrm{Eu}_{0.5} \mathrm{~Tb}_{9.5}(\mathrm{HFA})_{\mathrm{n}} @ \mathrm{ZY}, \\
\mathrm{Eu}_{1} \mathrm{~Tb}_{9}(\mathrm{HFA})_{\mathrm{n}} @ \mathrm{ZY}, \\
\mathrm{Eu}_{2} \mathrm{~Tb}_{8}(\mathrm{HFA})_{\mathrm{n}} @ \mathrm{ZY},\end{array}$} & \multirow{10}{*}{ vapor } & TEA & Red shift $^{c}$ & $b^{b}$ & \multirow{10}{*}{42} \\
\hline & & CYA & Red shift $^{c}$ & $b^{b}$ & \\
\hline & & BY & Red shift ${ }^{c}$ & $b$ & \\
\hline & & AN & Red shift $^{c}$ & $b$ & \\
\hline & & $\mathrm{NH}_{3}$ & Red shift $^{c}$ & $b$ & \\
\hline & & PDA & Red shift $^{c}$ & $b$ & \\
\hline & & NMA & Red shift $^{c}$ & $b$ & \\
\hline & & EA & Red shift $^{c}$ & $b$ & \\
\hline & & EDA & Red shift $^{c}$ & $b$ & \\
\hline & & MA & $\operatorname{Red~shift~}^{c}$ & $b$ & \\
\hline $\mathrm{Zn}_{2}(\mathrm{TCPE})$ & \multirow{2}{*}{ vapor } & $\mathrm{NH}_{3}$ & Red shift $\sim 24$ & $b$ & \multirow{2}{*}{43} \\
\hline $\mathrm{Mg}\left(\mathrm{H}_{2} \mathrm{DHBDC}\right)$ & & $\mathrm{NH}_{3}$ & Red shift $\sim 8$ & b & \\
\hline [ $\left.\mathrm{Zn}_{2}(\mathrm{TCPPE})(\mathrm{bib})\right]$ & vapor & $\mathrm{NH}_{3}$ & Red shift $\sim 19$ & b & 44 \\
\hline $\begin{array}{l}{\left[\mathrm{Zn}_{2}(\mathrm{MPIDA})_{2}\left(4,4^{\prime} \text {-bipy }\left(\mathrm{H}_{2} \mathrm{O}\right)_{4}\right]\right.} \\
\cdot 3 \mathrm{H}_{2} \mathrm{O}\end{array}$ & vapor & $\mathrm{NH}_{3}$ & Red shift $\sim 3$ & b & 45 \\
\hline $\mathrm{Zn}\left[\mathrm{Au}(\mathrm{CN})_{2}\right]_{2}$ & vapor & $\mathrm{NH}_{3}$ & Red shift $\sim 20$ & $b$ & 46 \\
\hline \multirow{5}{*}[\mathrm{Zn}(\mathrm{PA})(\mathrm{BPE})]{} & \multirow{5}{*}{ vapor } & EDA & Red shift $^{c}$ & $b$ & \multirow{5}{*}{47} \\
\hline & & n-BA & Red shift ${ }^{c}$ & b & \\
\hline & & DIPA & Red shift $^{c}$ & $b$ & \\
\hline & & TMEDA & Red shift ${ }^{c}$ & $b$ & \\
\hline & & TEA & Red shift $^{c}$ & $b$ & \\
\hline$\left.\left[\mathrm{Cd}_{2} \text { (pbpy)(bdc }\right)_{2} \mathrm{Cl}_{2}\right] .5 \mathrm{H}_{2} \mathrm{O}$ & & $\mathrm{NH}_{3}$ & Red shift $\sim 23$ & b & \\
\hline$\left[\mathrm{Cd}_{2}\right.$ (pbpy) $\left.(\mathrm{bdc})_{2} \mathrm{Br}_{2}\right] .8 \mathrm{H}_{2} \mathrm{O}$ & Vapor & $\mathrm{NH}_{3}$ & Red shift $\sim 25$ & b & 9 \\
\hline & & AN & Red shift $\sim 23$ & b & \\
\hline$\{[7 \mathrm{n}(\mathrm{ndc})(0-\mathrm{nh} n)] \cdot \mathrm{DMF}\}$ & $\mathrm{MeOH}$ & NMA & Red shift $\sim 119$ & $b^{b}$ & 48 \\
\hline$\{[\text { Zn(nac)(o-pnen) }) \cdot D M r\}_{n}$ & MIEUח & DMA & Red shift $\sim 149$ & b & 40 \\
\hline & & DMPT & Red shift $\sim 126$ & $\frac{b}{b}$ & \\
\hline & & $\mathrm{NH}_{3}$ & Red shift $^{d}$ & $(0.0505,0.0294)$ & \\
\hline $\mathrm{Eu}^{3+} 0.005-\mathrm{TTA} @ 1$ & yanor & EDA & Red shift $^{d}$ & $(0.0969,0.0826)$ & 49 \\
\hline & vapor & DEA & Red shift $^{d}$ & $(0.2226,0.1106)$ & 49 \\
\hline & & TEA & Red shift $^{d}$ & $c$ & \\
\hline$\left[\mathrm{Cd}(\mathrm{AS})_{2}(\text { phen })_{2}\right]$ EtOH $(1)$ & vapor & $\mathbf{N H}_{3}$ & Blue shift $\sim 85$ & $(0.1834,0.3330)$ & This work \\
\hline & & EDA & Blue shift $\sim 54$ & $(0.1399,0.2042)$ & \\
\hline
\end{tabular}


Abbreviations: $D M A=N, N^{\prime}$-dimethylacetamide, $n-B u N H_{2}$ or $n-B A=n$-butylamine, $t$-BuNH $H_{2}=$ tert-butylamine, $M A N=N$ methylaniline, $N M A=N$-methyl aniline, $D M A=N, N^{\prime}$-dimethyl aniline, TMEDA $=N, N$ '-dimethyl-p-toluidine, $N M A=N, N, N^{\prime}, N^{\prime}$ tetramethylethylenediamine, DIPA = diisopropylamine, $P D A=1,3$-propanediamine, $C Y A=$ cyclohexylamine, ${ }^{a}$ soaking in pyridine solution, ${ }^{b}$ the shift of emission color $(C I E-\Delta X, \Delta Y)$ was not reported, ${ }^{c}$ the shift of emission wavelength was not reported, ${ }^{d}$ detection at $100^{\circ} \mathrm{C}$

Moreover, the solid-state luminescent spectra of $1 @ \mathrm{NH}_{3}$ and $1 @$ EDA were compared with free ligands to confirm the formation of the charge transfer state upon addition of $\mathrm{NH}_{3}$ and EDA (Figure 5a). A red shift from the free ligands is observed in 1@ $\mathrm{NH}_{3}$ and 1@EDA, and thus further demonstrating that a distinct excited state is involved in the emission of $1 @ \mathrm{NH}_{3}$ and 1@EDA, i.e., likely the LLCT state. ${ }^{39-40}$ Compared with the emission of $\mathbf{1}$, the blue shifts of $1 @ \mathrm{NH}_{3}$ and 1@EDA can be attributed to an increase of charge transfer energy that could be observed in the solid-state UV-Vis absorption spectra. The positive shift of absorption band with the color change of $\mathbf{1}$ from yellow to colorless was observed after exposure to $\mathrm{NH}_{3}$ and EDA (Figure 5b). In addition, the occurrence of different emission wavelengths in $1 @ \mathrm{NH}_{3}$ and $1 @$ EDA is caused by varying charge transfer states in the different supramolecular frameworks of $1 @ \mathrm{NH}_{3}$ and $1 @ E D A$.

Furthermore, to evaluate the effect of basic condition on the sensing property of $\mathbf{1}$, the $\mathrm{pH}$ dependent luminescent spectra of $\mathbf{1}$ were analyzed under the same experimental sensing condition. The results show that the luminescence of $\mathbf{1}$ remains unchanged after exposure in the $\mathrm{pH}$ of 7-14 for $2 \mathrm{~h}$ (Figure S6). Therefore, the change of emission color upon exposure to $\mathrm{NH}_{3}$ and EDA is not caused by the basicity of the amine solution. Also, the sensing experiments of free phen and free NaAS ligands toward $\mathrm{NH}_{3}$ and EDA have been performed (Figure S7). The shift of emission spectra was not observed. This result confirms that the supramolecular interactions between amines and $\mathbf{1}$ play a key role for the discriminatively and selectively luminescent sensing of $\mathrm{NH}_{3}$ and EDA.

Considering the selectivity of $\mathbf{1}$ toward $\mathrm{NH}_{3}$ and EDA, it seems that the luminescent response can be correlated with the molecular size and the hydrogen bonding ability of both amines. Among the chosen amine molecules, $\mathrm{NH}_{3}$ shows the smallest size, so that it can easily access to the crystalline lattice of $\mathbf{1}$ and it potentially could form strong hydrogen bonds with the ligands, and thus inducing a structural transformation. Although the molecular size of EDA is larger than methyl and ethyl amines, the flexible molecular shape together with the higher number of $-\mathrm{NH}_{2}$ groups in EDA may well stabilize the final supramolecular structure of 1@EDA. ${ }^{51}$ For the bulkier amines, the change of emission color was not observed. This is likely due to their larger steric-hindrance with $\mathbf{1}^{3,52}$ 
(a)

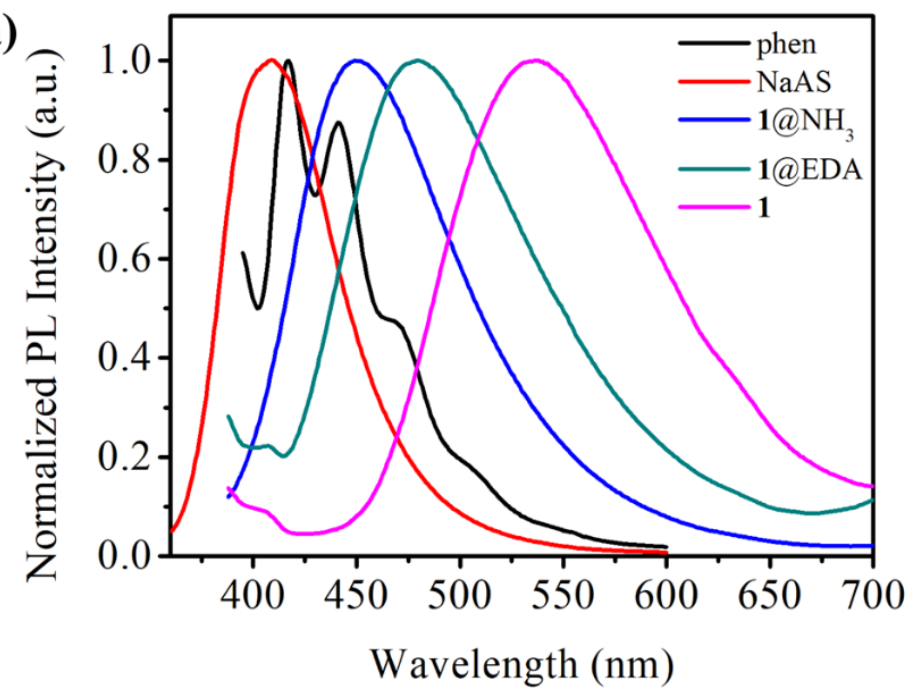

(b)

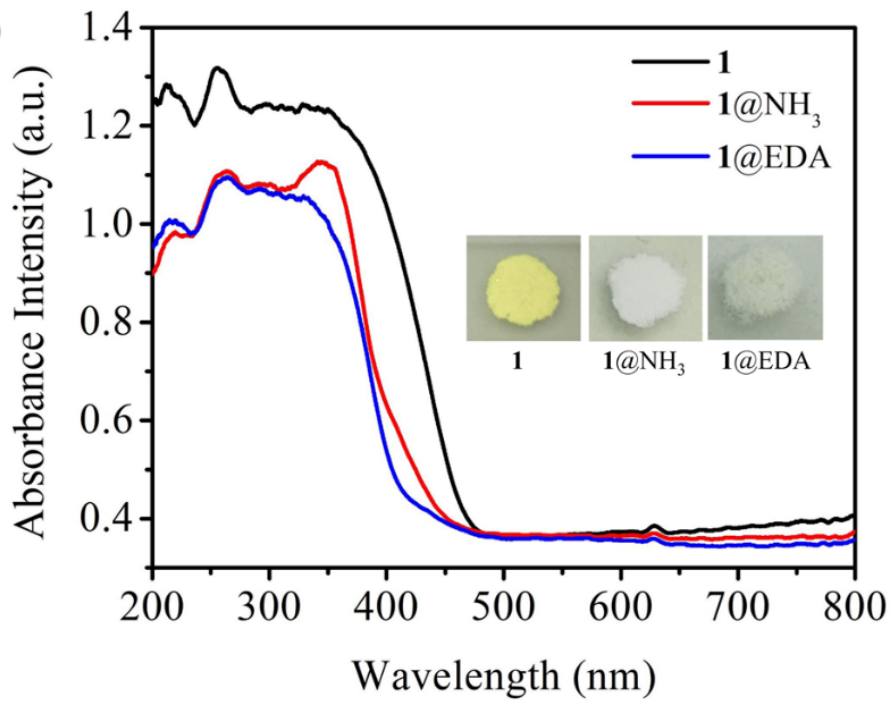

Figure 5. (a) The solid-state PL spectra of 1, 1@EDA, $1 @ \mathrm{NH}_{3}\left(\lambda_{\text {ex }} 368 \mathrm{~nm}\right)$, and free ligands ( $\lambda_{\text {ex }} 375 \mathrm{~nm}$ for phen and $\lambda_{\text {ex }} 344 \mathrm{~nm}$ for NaAS). (b) The solid-state UV-Vis absorption spectra of 1, 1@EDA, 1@NH

Luminescent sensing mechanism. To elucidate the luminescent sensing mechanism, IR spectra, PXRD patterns, and TGA of $\mathbf{1}$ exposed to amine vapors were investigated. Compared with the IR spectra of 1, 1@NH $\mathrm{NH}_{3}$ and 1@EDA show the additional peaks around 900-1000 cm${ }^{1}$ and the shift of $v\left(\mathrm{NH}_{2}\right)$ peaks, indicating the presence of $\mathrm{NH}_{3}$ and EDA molecules in crystal lattice of 1 (Figure S8). ${ }^{43}$ Moreover, the characteristic peaks of $v(\mathrm{OH}), \delta(\mathrm{OH})$ and $v(\mathrm{C}-\mathrm{O})$ of the lattice ethanol were observed, suggesting that the EtOH molecule still existed (Figure S8). The characteristic peaks of free phen and free AS ligands were not observed (Figure S9-S11). The results suggest that the coordinated ligands are not replaced by amines in which the amines are only incorporated in crystal lattice of $\mathbf{1}$. The significant change of the PXRD patterns from that of the original 1 was clearly observed in $1 @ \mathrm{NH}_{3}$ and $1 @ \mathrm{EDA}$, while the PXRD patterns 
treated by other amine vapors match well with the original pattern of 1 (Figure S12 and S13). The number of amines and lattice molecules containing in $1 @ \mathrm{NH}_{3}$ and $1 @ E D A$ structures was confirmed by thermogravimetric analysis. The thermograms reveal that $\mathbf{1} @ \mathrm{NH}_{3}$ continuously loses two AS, one $\mathrm{NH}_{3}$, one $\mathrm{H}_{2} \mathrm{O}$ and one $\mathrm{EtOH}$ molecules until $337^{\circ} \mathrm{C}$ (found: $44.51 \%$, calc.: $44.90 \%$ ), while the loss of two AS, two EDA and one EtOH molecules was found upon heating 1@EDA to $341^{\circ} \mathrm{C}$ (found: $50.04 \%$, calc.: $49.87 \%$ ) (Figure S14). This approximately confirmed the formula of $1 @ \mathrm{NH}_{3}$ and 1@EDA to be $\left[\mathrm{Cd}(\mathrm{AS})_{2}(\text { phen })_{2}\right] \mathrm{EtOH}\left(\mathrm{NH}_{3}\right)\left(\mathrm{H}_{2} \mathrm{O}\right)$ and $\left[\mathrm{Cd}(\mathrm{AS})_{2}(\text { phen })_{2}\right] \mathrm{EtOH}(\mathrm{EDA})_{2}$, respectively. The thermograms of 1@ $\mathrm{NH}_{3}$ and 1@EDA clearly showed weight loss below $160^{\circ} \mathrm{C}$ compared to 1 . This is due to the significant structural disparity between them. According to the crystal structure, the Cd(II) center of $\mathbf{1}$ is fully coordinated by the ligands showing the high coordination number $(\mathrm{CN}=7)$ and the release of free ligands was not observed after exposure of amine vapors. This is confirmed by both TGA and IR results. Thus, the sensing mechanism of 1 could occur via the change of bond distances and angles within the coordination sphere together with rearrangement of a supramolecular framework of 1 triggered by $\mathrm{NH}_{3}$ and EDA molecules that finally cause a shift in the emission color.

Computational study. To gain insights into the electronic structures, photophysical properties, and sensing mechanism for $\mathrm{NH}_{3}$ and EDA of $\mathbf{1}$, DFT and TD-DFT calculations were also carried out to analyze the supramolecular interactions between the amine molecules and the coordination sphere of 1 causing the emission spectral change (see the computational details in the experimental section). $\mathrm{S}_{0}$ and $\mathrm{S}_{1}$ optimizations of 1, $1 @ \mathrm{NH}_{3}$, and 1@EDA were systematically computed at B3LYP/6-31G(d) and TD-B3LYP/6-31G(d) levels, respectively, (Figure 6a-f). As molecular models for 1@ $\mathrm{NH}_{3}$ and 1@EDA, we selected $\left[\mathrm{Cd}(\mathrm{AS})_{2}(\text { phen })_{2}\right] \mathrm{EtOH}\left(\mathrm{NH}_{3}\right)\left(\mathrm{H}_{2} \mathrm{O}\right)$ and $\left[\mathrm{Cd}(\mathrm{AS})_{2}(\text { phen })_{2}\right] \mathrm{EtOH}(\mathrm{EDA})_{2}$, as suggested by the TGA experiments. Frontier molecular orbital (MOs) of $\mathbf{1}$ indicates that the highest occupied molecular orbital (HOMO) corresponds to a $\pi$ orbitals of the AS ligand, while the lowest unoccupied molecular orbital (LUMO and LUMO +5 ) correspond to $\pi^{*}$ orbitals located at the phen ligand (Figure 6g). According to the analysis, the photoluminescence of 1 should be attributed to $\mathrm{S}_{1}$, which is a LLCT state (see Table 3). ${ }^{41,53}$ After adding amine molecules into the crystal lattice of $\mathbf{1}$, the $\mathrm{S}_{0}$ and $\mathrm{S}_{1}$ optimized geometries of $1 @ \mathrm{NH}_{3}$, and 1@EDA indicate that the $\mathrm{NH}_{3}, \mathrm{H}_{2} \mathrm{O}$, and EDA molecules can coexist in the crystal lattice via the intermolecular noncovalent interactions with the functional groups of the ligands. This phenomenon leads to the change of bond lengths and bond angles around metal centers of 1@ $\mathrm{NH}_{3}$, and 1@EDA 
compared with the original structure 1 (see Table S6). For instance, in the $\mathrm{S}_{1}$ optimized geometry, the $\mathrm{Cd}-\mathrm{N} 1, \mathrm{Cd}-\mathrm{N} 2, \mathrm{Cd}-\mathrm{O} 1$, and $\mathrm{Cd}-\mathrm{O} 2$ bond lengths of $1 @ \mathrm{NH}_{3}$ and $1 @ E D A$ are shortened while Cd-N3, Cd-N4,Cd-O3, and Cd-O4 of 1@ $\mathrm{NH}_{3}$ and 1@EDA are lengthened, as compared with original structure 1. The positions of the vapor molecules after the optimization and the intermolecular interactions between the vapor and $\mathbf{1}$ are displayed in Figure S15 and summarized in Table S7. Different noncovalent interactions are presented in the $1 @ \mathrm{NH}_{3}$ and $1 @ E D A$ complexes. $\mathrm{NH}_{3}$ is certainly smaller than EDA and it interacts with the inner hydroxyl oxygen atom from chelating AS ligand. Conversely, the larger EDA molecules preferentially interact with the peripheral amino and hydroxyl groups from chelating and monodentate AS ligands, respectively. This leads to the difference of bond lengths and bond angles around metal centers of $1 @ \mathrm{NH}_{3}$ and $1 @ E D A$ (compare e.g., in Table S6 a Cd-O2 bond length of ca. $3.4 \AA$ in the $\mathrm{S}_{1}$ optimized geometry of $1 @ \mathrm{NH}_{3}$ versus a $\mathrm{Cd}-\mathrm{O} 2$ bond length of ca. $2.5 \AA$ for 1@EDA). According to the analysis of the intermolecular noncovalent interactions, the positions of the vapor molecules are gradually changed in the $\mathrm{S}_{1}$ state. For instance, the intermolecular hydrogen bond of $1 @ \mathrm{NH}_{3}$ (D1 and D3, see Figure S15 and Table S7) are elongated from 2.228 and $1.905 \AA$ in the $\mathrm{S}_{0}$ optimized geometry to 2.579 and $1.951 \AA$ in $\mathrm{S}_{1}$ optimized geometry, while $\mathrm{D} 2$ is shortened from $2.571 \AA$ in $\mathrm{S}_{0}$ state to $2.315 \AA$ in $\mathrm{S}_{1}$ state. Conversely, in the case of $1 @$ EDA, both intermolecular hydrogen bonds (D1 and D2) become shortened in $\mathrm{S}_{1}$ state. The alteration of coordination environment around metal centers results in the change of LLCT transition energy. MOs of 1@NH $\mathrm{NH}_{3}$ and 1@EDA (HOMO and LUMO) show that the electron density is mainly distributed on the orbitals of the ligands (Figure $6 \mathrm{~h}$ and i), implying that the luminescence of $\mathbf{1}$ after incorporating amine molecules in the lattice is originated from similar LLCT states. Interestingly, the simulated emission maxima of $\mathbf{1}$, 1@ $\mathrm{NH}_{3}$, and 1@EDA (Figure S16) are in reasonable agreement with the experimental ones as summarized in in Table 3. Additionally, the large blue shifts in the calculated emission spectra of $1 @ \mathrm{NH}_{3}$ and 1@EDA compared with respect of 1 are also comparable, indicating that the molecular lattices play an important role on the luminescence properties of the $\mathrm{Cd}(\mathrm{II})$ metal complex. The minor inconsistencies between the computed emission energies and the experimental ones is attributed to the packing framework that has not been considered in the calculation. ${ }^{54}$ Furthermore, to clarify the effect of EtOH molecule in the crystal lattice of $\mathbf{1}$ in these phenomena, the $\mathrm{S}_{0}$ and $\mathrm{S}_{1}$ geometries of 1@ $\mathrm{NH}_{3}$ and 1@EDA-adducted molecular models without EtOH in crystal lattice were optimized and their MOs were computed (Figure S17). The simulated emission maxima of both models are significantly different with the experimental results as summarized in Table S8, implying that the effect of hydrogen 
bonding between 1 and lattice molecules plays an important role on the shift of the photoluminescence in this interesting system. The calculated results confirm that $\mathrm{NH}_{3}$ and EDA molecules can interact with the framework of 1 via different noncovalent interactions, inducing the change of coordination bond length and bond angle around metal centers leading to the rearrangement of a supramolecular framework, and causing the shift of photoluminescence.

Sensitivity and reusability. The response time of a sensor also plays an important role for the practical applications. The time dependent luminescence of the sensor toward $\mathrm{NH}_{3}$ and EDA analytes were also investigated. As illustrated in Figure $7 \mathrm{a}$ and $7 \mathrm{~d}$, the blue-shift in the emission spectrum of 1 was completed within $30 \mathrm{~min}$, and 75 min after exposure to saturated $\mathrm{NH}_{3}$ and EDA vapors, respectively. Notably, the supramolecular structure of $\mathbf{1}$ was continuously transformed to $1 @ \mathrm{NH}_{3}$ and $1 @$ EDA upon increasing exposure time, which was confirmed by PXRD patterns (Figure 7c and 7f) resulting in the mix of emission color change at time intervals (Figure $7 \mathrm{~b}$ and $7 \mathrm{e}$ ). In order to assess the sensitivity of $\mathbf{1}$, the emission response after exposure to $\mathrm{NH}_{3}$ and EDA vapors generated from varying concentrations of the amine solutions was carried out. Compound 1 only displayed a blue-shift in the emission spectrum at high EDA concentration range of $58-99 \%$ (v/v) (Figure S18c and d). In contrast, the blueshifted emission spectrum of 1 for $\mathrm{NH}_{3}$ was initially found upon exposure to $8 \%$ (v/v) $\mathrm{NH}_{3}$, and the spectrum was completely shifted upon reaching the concentration of $16 \%(\mathrm{v} / \mathrm{v})$ (Figure $\mathrm{S} 18 \mathrm{a}$ and $\mathrm{b})$. Therefore, the limit of detection (LOD) is $8(\mathrm{v} / \mathrm{v})$ for $\mathrm{NH}_{3}$ and $58 \%(\mathrm{v} / \mathrm{v})$ for EDA solutions, which is calculated to be about 1.1 and $2.2 \mathrm{mmol} / \mathrm{cm}^{3}$ for concentration of $\mathrm{NH}_{3}$ and EDA vapors in the vial, respectively. ${ }^{17,39}$ The different response time and sensitivity between $\mathrm{NH}_{3}$ and EDA is attributed to their different molecular sizes based on the reason that the larger molecule of EDA generally generates the lower vapor pressure, and EDA also reveals a higher steric-hindrance with $\mathbf{1}^{2,22}$ 
$\mathrm{S}_{0}$ optimized geometries

(a)

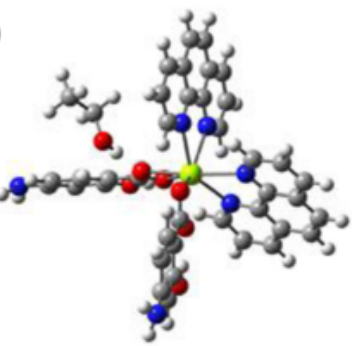

$\mathrm{S}_{1}$ optimized geometries

(d)

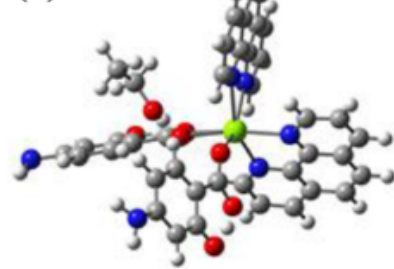

(g)

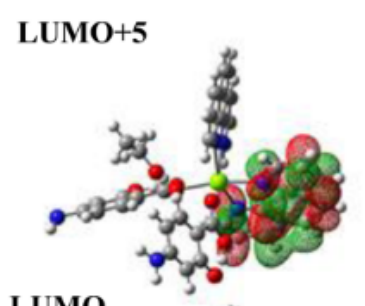

LUMO
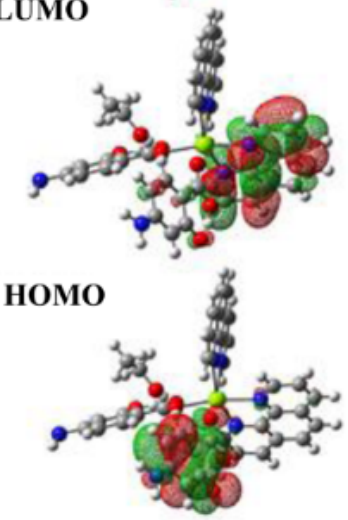

1
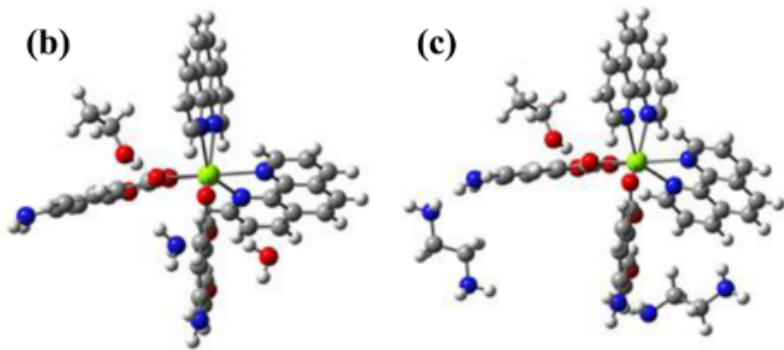

(e)

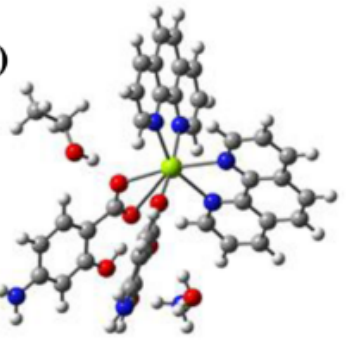

(h)

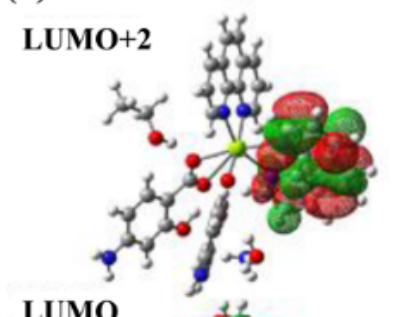

LUMO

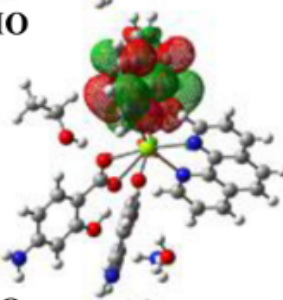

HOMO

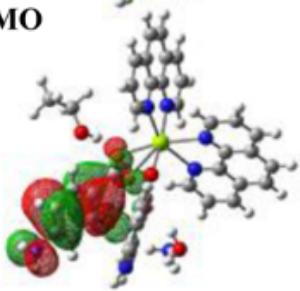

1@ $\mathrm{NH}_{3}$

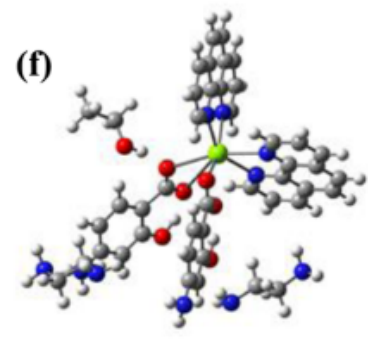

(i)
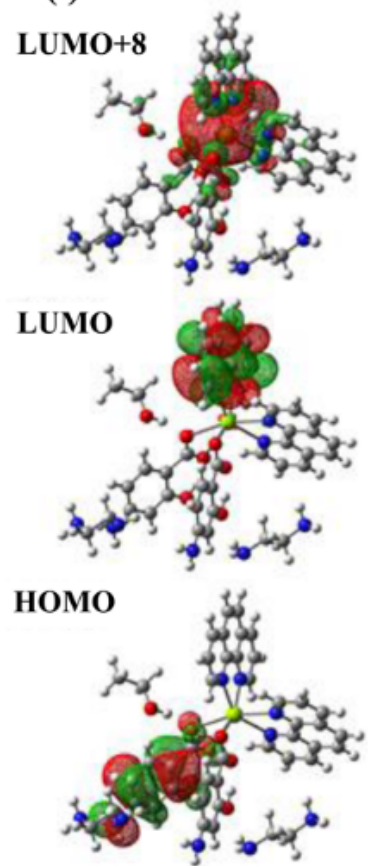

1@EDA

Figure 6. Optimized geometries of 1, $1 @ \mathrm{NH}_{3}$, and $1 @ E D A$ in $\mathrm{S}_{0}(\mathrm{a})-(\mathrm{c})$ and $\mathrm{S}_{1}(\mathrm{~d})-(\mathrm{f})$.

Contour plots of HOMO and LUMO of $1(\mathrm{~g}), \mathbf{1} @ \mathrm{NH}_{3}(\mathrm{~h})$, and $1 @ E D A(\mathrm{i})$ at $\mathrm{S}_{1}$ optimized geometries computed at TD-B3LYP/6-31G(d) level. 
Table 3. Calculated maximum emission wavelength (nm), the comparison of calculated and experimental wavelength $(\mathrm{nm})$, and molecular orbital contributions of 1, 1@ $\mathrm{NH}_{3}$, and $1 @$ EDA at $\mathrm{S}_{1}$ optimized geometries (TD-B3LYP/6-31G(d)).

\begin{tabular}{llll}
\hline \multirow{2}{*}{ Complex } & \multicolumn{2}{c}{ Emission } & \\
\cline { 2 - 4 } & $\begin{array}{l}\text { Exp. } \\
\lambda_{\max }(\mathbf{n m})\end{array}$ & $\begin{array}{l}\text { Cal. } \\
\boldsymbol{\lambda}_{\max }(\mathbf{n m})\end{array}$ & MOs Contribution of $\mathbf{S}_{\mathbf{1}}(\mathbf{\%})$ \\
\hline $\mathbf{1}$ & 534 & 527 & HOMO $\rightarrow$ LUMO $5(100 \%)$ \\
\hline $\mathbf{1} @ \mathrm{NH}_{3}$ & 449 & 417 & HOMO-5 $\rightarrow$ LUMO+2 (93\%) \\
$\mathbf{1} @ \mathrm{EDA}$ & 480 & 482 & HOMO $\rightarrow$ LUMO+8 $(98 \%)$ \\
\hline
\end{tabular}

(a)

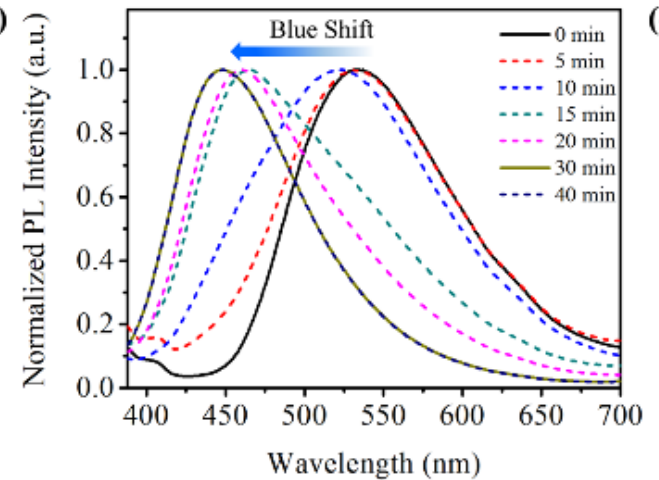

(b)

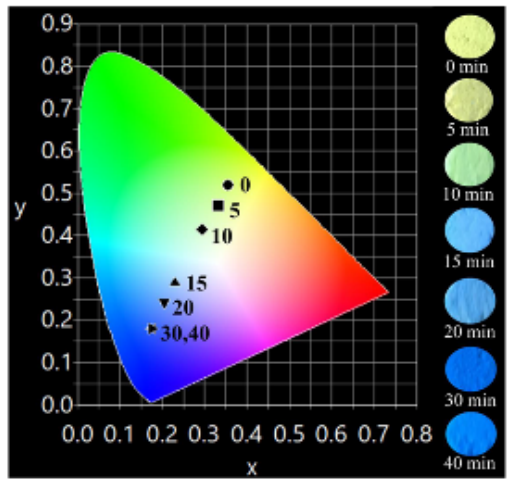

(c)

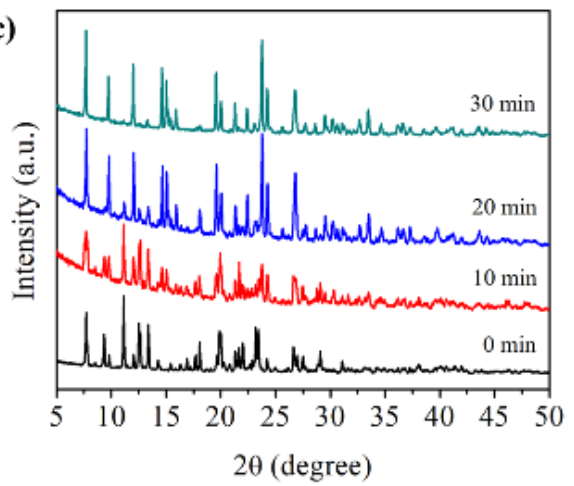

(d)

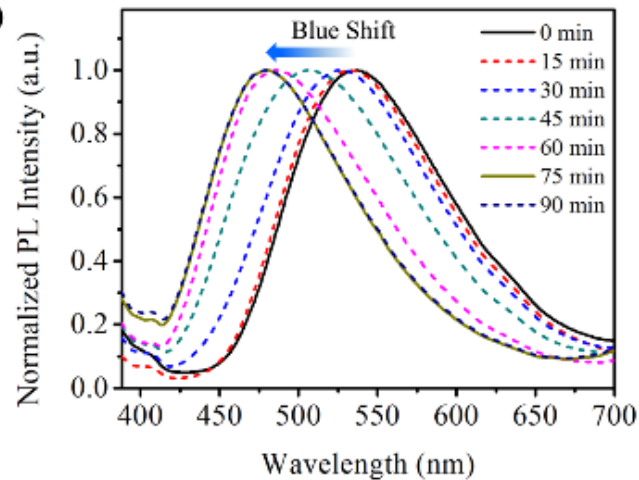

(e)

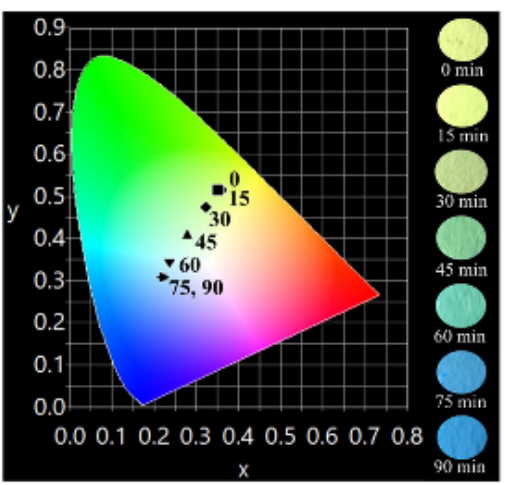

(f)

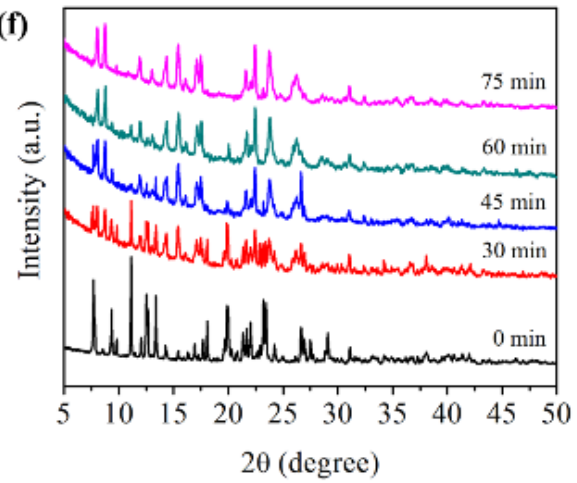

Figure 7. The blue shift of solid-state luminescent bands ( $\left.\lambda_{\text {ex }} 368 \mathrm{~nm}\right)$, CIE chromaticity coordinates, and the PXRD patterns of $1 @ \mathrm{NH}_{3}(\mathrm{a}, \mathrm{b}, \mathrm{c})$ and 1@EDA $(\mathrm{d}, \mathrm{e}, \mathrm{f})$ at different interval times. 
The recyclability of 1 for sensing $\mathrm{NH}_{3}$ and EDA vapors were also examined. Indeed, upon exposure of $1 @ \mathrm{NH}_{3}$ in saturated EtOH vapor for $3 \mathrm{~h}$, the original structure of 1 was recovered (denoted as 1@EtOH) and, the emission color and crystalline framework of 1 were completely returned after these experiments (Figure 8 and S19-S20). Conversely, for EDA sensing, the recovered crystalline phase cannot be obtained. This is probably a result from the stronger intermolecular interaction between EDA and the framework. However, after soaking 1@EDA in EtOH solution for 24h, 1 could be recovered (Figure S21-S23). In addition, the luminescence response to $\mathrm{NH}_{3}$ and EDA can be repeated for 5 cycles in which the emission color was consistent in both the shift and the regenerated state, demonstrating the reusability of $\mathbf{1}$. According to the recyclability results, this is an important consideration that $\mathbf{1}$ can be used as an efficient reversible sensor for the detection of $\mathrm{NH}_{3}$ and EDA for practical applications.
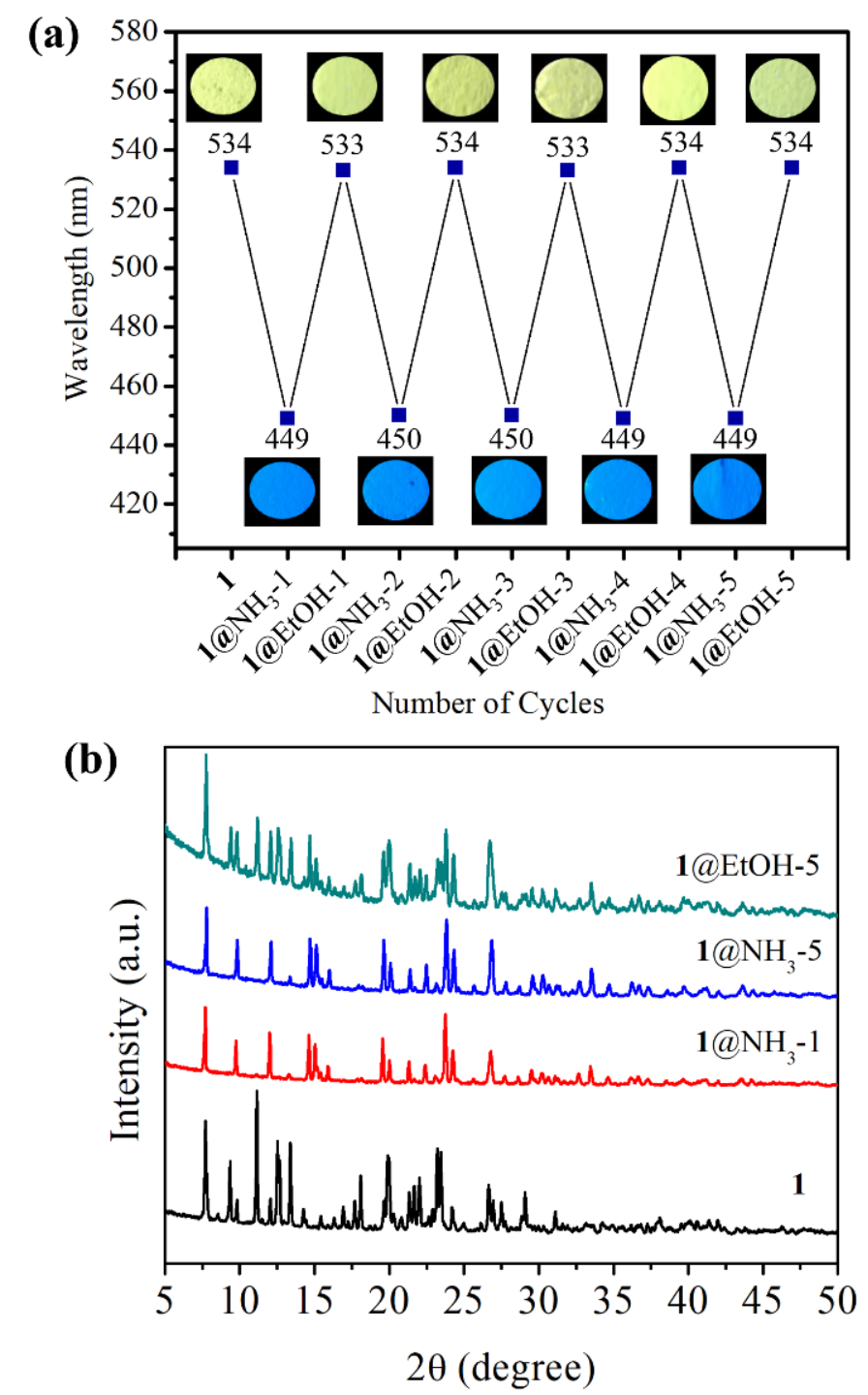

Figure 8. (a) Representation of the reversible luminescent response ( $\left.\lambda_{\text {ex }} 368 \mathrm{~nm}\right)$, and (b) the recovered PXRD patterns of $\mathbf{1}$. 


\section{CONCLUSIONS}

In summary, a novel solid-state luminescent supramolecular coordination framework of $\mathbf{1}$ containing mixed luminorphores was prepared at room temperature. The supramolecular structure is well stabilized by various noncovalent interactions between the adjacent free functional groups on the luminophore ligands. The solid-state luminescent 1 exhibited a high selective sensing for $\mathrm{NH}_{3}$ and EDA without other interferences, showing discriminatively and visibly luminescent color change. The sensing process occurred via the rearrangement of the noncovalent interactions and structural transformation triggered by the contact of the small amine molecules with the framework. This phenomena produces a shift in the energy of the charge transfer state, eventually leading to the shift of emission color. The sensing mechanism was confirmed by the computational studies, in which the experimental observations were well consistent with the theoretical calculations. Moreover, 1 also displayed a high recyclability for $\mathrm{NH}_{3}$ and EDA vapor, showing a practical use for solid-state luminescent sensor.

\section{ASSOCIATED CONTENT}

Supporting Information. X-ray crystallographic data 1 in CIF format, crystallographic data were deposited with the CCDC no. 1962656. Supplementary material available: crystal structure, FT-IR spectra, thermograms, PXRD, photoluminescence spectra, computational results and other data (Scheme S1, Table S1-S8, Figure S1-S23) (PDF).

\section{AUTHOR INFORMATION}

\section{Corresponding Authors}

*E-mail: Jaursup@kku.ac.th; fax: +6643-202-373.

\section{ACKNOWLEDGMENT}

This work was financially supported by the grant from the Thailand Research Fund: Grant No. RSA6180060, and the Center of Excellence for Innovation in Chemistry (PERCH-CIC), Office of the Higher Education Commission, Ministry of Education, Thailand. S. Tunsrichon would like to thank The Development and Promotion of Science and Technology Talents Project (DPST) for Ph.D. scholarship. C. Sukpattanacharoen would like to thank The Science 
Achievement Scholarship of Thailand (SAST) for Ph.D. fellowship. Graduate School of Chiang Mai University, Chiang Mai, Thailand is also acknowledged. N. Kungwan would like to thank Chiang Mai University for partially financial support. D. Escudero acknowledges funding from Internal Funds KU Leuven.

\section{REFERENCES}

1. Timmer, B.; Olthuis, W.; Berg, A. V. D. Ammonia sensors and their applications-a review. Sensor Actuat B Chem. 2005, 107, 666-677.

2. Shen, M. L.; Wei, Z.; Xu, L.; Liu, B.; Jiao, H. A mixed matrix Eu-4,4'biphenyldicarboxylate coordination polymer film as a fluorescence turn-off sensor to aniline vapor. J. Solid State Chem. 2019, 269, 87-93.

3. Sui, Q.; Li, P.; Yang, N.-N.; Gong, T.; Bu, R.; Gao, E.-Q. Differentiable detection of volatile amines with a viologen-derived metal-organic material. ACS Appl. Mater. 2018, 10, 11056-11062.

4. Fiddes, L. K.; Chang, J.; Yan, N. Electrochemical detection of biogenic amines during food spoilage using an integrated sensing RFID tag. Sensor Actuat B Chem. 2014, 202, 1298 1304.

5. Lin, J.-F.; Kukkola, J.; Sipola, T.; Raut, D.; Samikannu, A.; Mikkola, J.-P.; Mohl, M.; Toth, G.; Su, W.-F.; Laurila, T.; Kordas, K. Trifluoroacetylazobenzene for optical and electrochemical detection of amines. J. Mater. Chem. A. 2015, 3, 4687-4694.

6. Basabe-Desmonts, L.; Reinhoudt, D. N.; Crego-Calama, M. Design of fluorescent materials for chemical sensing. Chem. Soc. Rev. 2007, 36, 993-1017.

7. Vellingiri, K.; Boukhvalov, D. W.; Kim, K.-H.; Philip, L. Validation of 'lock-and-key' mechanism of a metal-organic framework in selective sensing of triethylamine. RSC $A d v$. 2019, 9, 7818-7825.

8. Shen, N.; Li, J.; Li, G.; Hu, B.; Li, J.; Liu, T.; Gong, L.; Huang, F.; Wang, Z.; Huang, X. Designing polymorphic $\mathrm{Bi}^{3+}$-containing ionic liquids for stimuli-responsive luminescent materials. Inorg. Chem. 2019, 58, 8079-8085.

9. Chen, C.; Cai, L.-X.; Tan, B.; Zhang, Y.-J.; Yang, X.-D.; Zhang, J. Ammonia detection by using flexible Lewis acidic sites in luminescent porous frameworks constructed from a bipyridinium derivative. Chem. Commun. 2015, 51, 8189-8192.

10. Jaros, S. W.; Sokolnicki, J.; Wołoszyn, A.; Haukka, M.; Kirillov, A. M.; Smoleński, P. A novel 2D coordination network built from hexacopper(I)-iodide clusters and cagelike 
aminophosphine blocks for reversible "turn-on" sensing of aniline. J. Mater. Chem. C. 2018, 6, 1670-1678.

11. Li, P.; Li, H. Amine vapor responsive lanthanide complex entrapment: control of the ligand-to-metal and metal-to-metal energy transfer. J. Mater. Chem. C. 2016, 4, 2165-2169.

12. Zhang, H.; Yang, J.; Liu, Y.-Y.; Song, S.; Ma, J.-F. A family of metal-organic frameworks with a new chair-conformation resorcin[4]arene-based ligand: selective luminescent sensing of amine and aldehyde vapors, and solvent-mediated structural transformations. Cryst. Growth Des. 2016, 16, 3244-3255.

13. Carballo, R.; Covelo, B.; Gómez-Paz, O.; Lago, A. B.; Vázquez-López, E. M. Supramolecular metal-organic frameworks based on neutral and cationic copper(II) $\alpha$ hydroxycarboxylate complexes with 2,2'-dipyridylamine. Polyhedron 2018, 154, 398-406.

14. Sun, D.; Cao, R.; Sun, Y.; Bi, W.; Li, X.; Wang, Y.; Shi, Q.; Li, X. Novel silvercontaining supramolecular frameworks constructed by combination of coordination bonds and supramolecular interactions. Inorg. Chem. 2003, 42, 7512-7518.

15. Allendorf, M. D.; Bauer, C. A.; Bhakta, R. K.; Houk, R. J. T. Luminescent metal-organic frameworks. Chem. Soc. Rev. 2009, 38, 1330-1352.

16. Mako, T. L.; Racicot, J. M.; Levine, M. Supramolecular luminescent sensors. Chem. Rev. 2019, 119, 322-477.

17. Li, Y.-P.; Li, S.-N.; Jiang, Y.-C.; Hu, M.-C.; Zhai, Q.-G. A semiconductor and fluorescence dual-mode room-temperature ammonia sensor achieved by decorating hydroquinone into a metal-organic framework. Chem. Commun. 2018, 54, 9789-9792.

18. Chen, J.; Yi, F.-Y.; Yu, H.; Jiao, S.; Pang, G.; Sun, Z.-M. Fast response and highly selective sensing of amine vapors using a luminescent coordination polymer. Chem. Commun. 2014, 50, 10506-10509.

19. Yang, N.-N.; Zhou, L.-J.; Li, P.; Sui, Q.; Gao, E.-Q. Space-confined indicator displacement assay inside a metal-organic framework for fluorescence turn-on sensing. Chem. Sci. 2019, 10, 3307-3314.

20. Wenger, O. S. Vapochromism in organometallic and coordination complexes: chemical sensors for volatile organic compounds. Chem. Rev. 2013, 113, 3686-3733.

21. Field, J. S.; Grimmer, C. D.; Munro, O. Q.; Waldron, B. P. Speciation in solution, solid state spectroscopy and vapochromism of $[\mathrm{Pt}(\operatorname{trpy})(\mathrm{NCS})] \mathrm{SbF}_{6}$ where trpy $=2,2^{\prime}: 6^{\prime}, 2^{\prime \prime}-$ terpyridine. Dalton Trans. 2010, 39, 1558-1567. 
22. Wadas, T. J.; Wang, Q.-M.; Kim, Y.-j.; Flaschenreim, C.; Blanton, T. N.; Eisenberg, R. Vapochromism and its structural basis in a luminescent $\mathrm{Pt}(\mathrm{II})$ terpyridine-nicotinamide complex. J. Am. Chem. Soc. 2004, 126, 16841-16849.

23. Lee, Y.-A.; Eisenberg, R. Luminescence tribochromism and bright emission in Gold(I) thiouracilate complexes. J. Am. Chem. Soc. 2003, 125, 7778-7779.

24. Baldauff, E. A.; Buriak, J. M. Optical sensing of amine vapors with a series of tin compounds. Chem. Commun. 2004, 18, 2028-2029.

25. Vaughan, A. A.; Baron, M. G.; Narayanaswamy, R. Optical ammonia sensing films based on an immobilized metalloporphyrin. Anal. Commun. 1996, 33, 393-396.

26. Abe, T.; Suzuki, T.; Shinozaki, K. Luminescence change by the solvent of crystallization, solvent reorganization, and vapochromism of neutral dicyanoruthenium(II) complex in the solid state. Inorg. Chem. 2010, 49, 1794-1800.

27. Zhang, X.; Li, B.; Chen, Z.-H.; Chen, Z.-N. Luminescence vapochromism in solid materials based on metal complexes for detection of volatile organic compounds (VOCs). $J$. Mater. Chem. 2012, 22, 11427-11441.

28. APEX2; Bruker AXS Inc.: Madison, WI, 2014.

29. SAINT 4.0 Software reference manual; Siemens Analytical X-Ray Systems Inc.: Madison, WI, 2000.

30. Sheldrick, G. M. SADABS, Program for Empirical Absorption correction of Area Detector Data; University of Göttingen: Göttingen, Germany, 2000.

31. Sheldrick, G. M. A short history of SHELX. Acta Crystallogr., Sect. A: Found. Crystallogr. 2008, A64, 112-122.

32. Becke, A. D. Density-functional exchange-energy approximation with correct asymptotic behavior. Phys. Rev. A. 1988, 38, 3098.

33. Becke, A. D. A new mixing of Hartree-Fock and local density- functional theories. $J$. Chem. Phys. 1993, 98, 1372.

34. Lee, C.; Yang, W.; Parr, R. G. Development of the Colle-Salvetti correlation-energy formula into a functional of the electron density. Phys. Rev. B. 1988, 37, 785.

35. Andrae, D.; Haeussermann, U.; Dolg, M.; Stoll, H.; Preuss, H. Energy-adjustedab initio pseudopotentials for the second and third row transition elements. Theor. Chim. Acta. 1990, $77,123-141$.

36. O'boyle, N. M.; Tenderholt, A. L.; Langner, K. M. Cclib: a library for packageindependent computational chemistry algorithms. J. Comput. Chem. 2008, 29, 839-845. 
37. Frisch, M.; Trucks, G.; Schlegel, H.; Scuseria, G.; Robb, M.; Cheeseman, J.; Scalmani, G.; Barone, V.; Petersson, G.; Nakatsuji, H. J. I., Wallingford CT, Gaussian 16, Revision A. 03, Gaussian. 2016.

38. Cui, Y.; Yue, Y.; Qian, G.; Chen, B. Luminescent functional metal-organic frameworks. Chem. Rev. 2012, 112, 1126-1162.

39. Yi, F.-Y.; Wang, Y.; Li, J.-P.; Wu, D.; Lan, Y.-Q.; Sun, Z.-M. An ultrastable porous metal-organic framework luminescent switch towards aromatic compounds. Mater. Horiz. 2015, 2, 245-251.

40. Fard, Z. H.; Kalinovskyy, Y.; Spasyuk, D. M.; Blight, B. A.; Shimizu, G. K. H. Alkalineearth phosphonate MOFs with reversible hydration-dependent fluorescence. Chem. Commun. 2016, 52, 12865-12868.

41. Lin, Y.-W.; Tong, Y.-P. One novel and unprecedented one-dimensional zinc coordination polymer with a N,O-donor chelating phenolic ligand, 3-n-butyl-2-(2-hydroxyphenyl)-3Hbenzimidazole: synthesis, structure, characterization, photoluminescence and theoretical calculations. Inorg. Chem. Commun. 2009, 12, 208-210.

42. Li, P.; Li, Z.; Yao, D.; Li, H. Colorimetric sensor arrays for amines based on responsive lanthanide complex entrapment. J. Mater. Chem. C. 2017, 5, 6805-6811.

43. Shustova, N. B.; Cozzolino, A. F.; Reineke, S.; Baldo, M.; Dincă, M. Selective turn-on ammonia sensing enabled by high-temperature fluorescence in metal-organic frameworks with open metal sites. J. Am. Chem. Soc. 2013, 135, 13326-13329.

44. Tao, C.-L.; Ying, Y.-M.; Wang, H.; Chen, B.; Zhu, G.-P.; Song, Y.-J.; Liu, X.-G.; Zhao, Z.; Shen, L.; Tang, B. Z. Nonwoven fabric coated with a tetraphenylethene-based luminescent metal-organic framework for selective and sensitive sensing of nitrobenzene and ammonia. $J$. Mater. Chem. C. 2018, 6, 12371-12376.

45. Miao, J.; Nie, Y.; Xiong, Z.; Chai, Y.; Fu, S.; Yan, H. Stimulus-responsive reversible thermochromism and exciplex emission of a $\mathrm{Zn}(\mathrm{II})$ complex and selective sensing of $\mathrm{NH}_{3}$ gas. Dalton Trans. 2019, 48, 5000-5006.

46. Katz, M. J.; Ramnial, T.; Yu, H.-Z.; Leznoff, D. B. Polymorphism of $\mathrm{Zn}\left[\mathrm{Au}(\mathrm{CN})_{2}\right]_{2}$ and its luminescent sensory response to $\mathrm{NH}_{3}$ vapor. J. Am. Chem. Soc. 2008, 130, 10662-10673.

47. Mani, P.; Ojha, A. A.; Reddy, V. S.; Mandal, S. "Turn-on" fluorescence sensing and discriminative detection of aliphatic amines using a 5-fold-interpenetrated coordination polymer. Inorg. Chem. 2017, 56, 6772-6775. 
48. Haldar, R.; Matsuda, R.; Kitagawa, S.; George, S. J.; Maji, T. K. Amine-responsive adaptable nanospaces: fluorescent porous coordination polymer for molecular recognition. Angew. Chem. 2014, 126, 11966-11971.

49. Shen, X.; Yan, B. A novel fluorescence probe for sensing organic amine vapors from a $\mathrm{Eu}^{3+} \beta$-diketonate functionalized bio-MOF-1 hybrid system. J. Mater. Chem. C. 2015, 3, 70387044.

50. Liu, L.; Dai, J.-C. $\left[\mathrm{Zn}(\mathrm{tp})(\mathrm{RdmB})\left(\mathrm{H}_{2} \mathrm{O}\right)\right]$ and $[\mathrm{Cd}(\mathrm{tp})(\mathrm{RdmB})]$ : two unusual onedimensional Rhodamine B coordination polymeric ribbons as luminescent sensors for small molecules and metal cations. Cryst. Growth Des. 2018, 18, 4460-4469.

51. Wang, S.; Liu, J.; Zhao, H.; Guo, Z.; Xing, H.; Gao, Y. Electrically conductive coordination polymer for highly selective chemiresistive sensing of volatile amines. Inorg. Chem. 2018, 57, 541-544.

52. Li, X.-N.; Li, L.; Wang, H.-Y.; Fu, C.; Fu, J.-W.; Sun, Y.-N.; Zhang, H. A novel photochromic metal-organic framework with good anion and amine sensing. Dalton Trans. 2019, 48, 6558-6563.

53. Li, R.; Zheng, F.-K.; Xiao, Y.; Zhao, Y.-P.; Xu, J.-G.; Yan, Y.; Guo, G.-C. Tunable dualemissive photoluminescence of a zinc(II) coordination polymer based on tetrazolatecarboxylatate acid and 4,4'-bipyridine mixed organic chromophores. Inorg. Chem. Commun. 2016, 70, 193-196.

54. Ghorai, P.; Dey, A.; Hazra, A.; Dutta, B.; Brandão, P.; Ray, P. P.; Banerjee, P.; Saha, A. $\mathrm{Cd}(\mathrm{II})$ based coordination polymer series: fascinating structures, efficient semiconductors, and promising nitro aromatic sensing. Cryst. Growth Des. 2019, 19, 6431-6447. 


\section{TABLE OF CONTENTS GRAPHIC AND SYNOPSIS.}

A novel Cd(II) supramolecular coordination framework (1) exhibited a selective luminescent sensing of $\mathrm{NH}_{3}$ and ethylenediamine (EDA) vapors through very large blue-shifted luminescent spectra with the naked-eye luminescent color change under UV light.

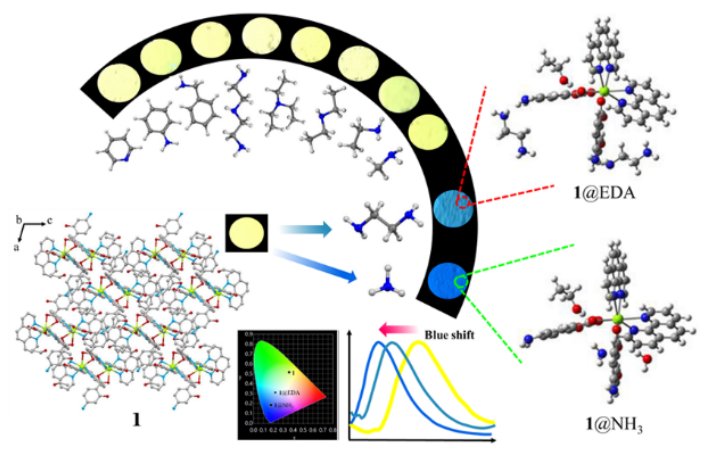

